\title{
Indications for Coronary Angiography
}

\author{
Karl Poon and Darren Walters \\ The Prince Charles Hospital \\ Australia
}

\section{Introduction}

Since the first serendipitous selective coronary angiography was performed by pediatric cardiologist Dr. Mason Sones in 1958 during ventriculography and aortography (Sones et al., 1959), invasive coronary angiography has become well established as the diagnostic gold standard for coronary artery disease.

Coronary angiography provides definitive information of "luminology" (radiographic outline using a contrast agent) of the coronary arteries. It is the standard with which other diagnostic modalities are compared. Millions are performed annually worldwide. Whilst the risk of coronary angiography of complications is very low in experienced hands the procedure is invasive and, requires dedicated infrastructure and expense. There are certain specific indications for coronary angiography. The general indication for a coronary angiography is to define the coronary artery anatomy. More detailed guidelines for coronary angiography date back to 1999 from the American College of Cardiology (Scanlon et al., 1999). This of course predated the enormous technological advancement over the past decade, the development in computed tomography coronary angiography, the widespread adoption of coronary stenting, the improvement afforded by drug eluting stents, and the availability of new antiplatelet therapy that enhanced the safety of all coronary interventions.

This chapter examines the appropriate indications for invasive coronary angiography in the current era, assesses the role of non invasive CT coronary angiography, and incorporates the emerging adjunctive role in the management of patients undergoing percutaneous cardiac structural interventions. Case vignettes are included in this chapter to illustrate the indications and use of coronary angiography in the current era.

It must be stressed whilst guidelines do provide recommendations regarding the indications for invasive coronary angiography, many more complex clinical and non clinical factors exist for each individual patient and the clinician must exercise clinical acumen to proceed to perform an invasive diagnostic and/or therapeutic procedure.

\section{Indications for coronary angiography}

Coronary angiography involves the opacification of the lumen in coronary arteries and acquisition of this luminogram under fluoroscopy. Consequently the indication for coronary angiography is predominantly focused on the diagnosis of any conditions that can lead to luminal compromise. This anatomical study defines the origin, course and pattern of 
epicardial arteries, with a spatial resolution that is still superior to other non-invasive imaging modalities. There are however limitations to coronary angiography. Aside from the obvious invasive nature and attendant risks, it provides only a projection of the lumen outlined by contrast and hence no information on the extent of atheroma contained within the vessel wall or the functional significance of the stenosis which can only be inferred. Both of these limitations can be overcome by the use of intravascular modalities such as intravascular ultrasound, optical coherence tomography and fractional flow reserve assessment. When combined with these adjuncts, coronary angiography serves as a formidable tool in guiding revascularization strategies, with a body of scientific data that has been well validated to provide long term prognostic benefit.

The guiding principle in determining the indication behind the decision to undertake coronary angiography in a given patients is similar to that underpinning the decision to undertake any invasive investigations in medicine. The decision to proceed is based on that the knowledge gained from the investigation outweighs the perceived risk, that the result will benefit the patient, in that it will likely change management and the available treatment option will improve symptoms and/or prognosis. The risks and complications of coronary angiography are covered elsewhere in this book and this chapter will focus on the indications of coronary angiography. Relative and absolute contraindications are also covered briefly.

The indications for coronary angiography have been divided into the follow clinical categories:

1. Coronary artery disease

1. Stable pattern

i. suspected coronary artery disease

ii. known coronary artery disease

2. Unstable pattern

i. Acute coronary syndrome with unstable haemodynamics or rhythm

ii. Unstable angina and Non-ST elevation MI

iii. ST elevation MI

iv. Out of hospital cardiac arrest

3. Special considerations

i. Congestive cardiac failure

ii. Preoperative assessment for non cardiac surgery

iii. The value of non invasive computed tomography coronary angiography

4. Relative and absolute contraindications

2. Prelude to structural cardiac disease/valvular heart disease intervention

3. Case vignettes of the use of coronary angiography in the contemporary era

\section{Coronary artery disease}

Coronary angiography is pivotal in the diagnostic algorithm as the gold standard for the confirmation of coronary artery stenosis. A number of well defined clinical scenarios often lead to the suspicion of coronary artery disease. This section is separated into patients who present in stable pattern, symptomatic or asymptomatic; and patients who present in an acute manner highly suggestive of coronary artery disease, i.e. acute coronary syndromes. Specifics scenarios, such as the role of coronary angiography in the 
investigation of congestive cardiac failure, pre-valvular surgery and the emerging role of computed tomography coronary angiography will be covered too.

\subsubsection{Coronary artery disease - stable pattern - suspected coronary artery disease}

The assessment of patients with symptoms suggestive of coronary artery disease (CAD) depends on three key factors: the clinical assessment of the quality of symptoms, the clinical risk profile, and the presence of existing abnormalities on surface electrocardiogram suggestive of CAD.

The ACC/AHA guidelines on exercise testing (Gibbons, 2002) provide classification of symptoms as typical, atypical angina and non-anginal chest pain (table 1). It is well known symptoms alone have a poor predictive value and differ between males and females (Hemingway et al, 2006, 2008). Combined with the underlying clinical risk profile however, a more reliable pre-test probability on CAD can be generated (table 2).

\begin{tabular}{ll}
\hline Chest pain & Definition \\
\hline Typical/definite angina & $\begin{array}{l}\text { Substernal chest pain or equivalent } \\
-\quad \text { Provoked by exertion or emotional stress }\end{array}$ \\
$\begin{array}{l}\text { Atypical/probable } \\
\text { angina }\end{array}$ & $\begin{array}{l}\text { Chest pain or discomfort with two characteristics of definite or } \\
\text { typical angina }\end{array}$ \\
Non-anginal chest pain & $\begin{array}{l}\text { Chest pain or discomfort that meets one or none of the typical } \\
\text { angina characteristics }\end{array}$ \\
\hline
\end{tabular}

Table 1. Classification of chest pain

\begin{tabular}{llllll}
\hline Age & Sex & $\begin{array}{l}\text { Typical/definite } \\
\text { angina }\end{array}$ & $\begin{array}{l}\text { Atypical/probable } \\
\text { angina }\end{array}$ & $\begin{array}{l}\text { Nonanginal } \\
\text { chest pain }\end{array}$ & Asymptomatic \\
\hline$<39$ & $\begin{array}{l}\text { Male } \\
\text { Female }\end{array}$ & $\begin{array}{l}\text { Intermediate } \\
\text { Intermediate }\end{array}$ & $\begin{array}{l}\text { Intermediate } \\
\text { Very low }\end{array}$ & $\begin{array}{l}\text { Low } \\
\text { Very low }\end{array}$ & $\begin{array}{l}\text { Very low } \\
\text { Very low }\end{array}$ \\
$40-$ & Male & High & Intermediate & Intermediate & Low \\
49 & Female & Intermediate & Low & Very low & Very low \\
$50-$ & Male & High & Intermediate & Intermediate & Low \\
59 & Female & Intermediate & Intermediate & Low & Very low \\
$>60$ & Male & High & Intermediate & Intermediate & Low \\
& Female & High & Intermediate & Intermediate & Low \\
\hline
\end{tabular}

Table 2. Pretest probability of coronary artery disease based on age, sex and symptoms (adapted from Gibbons et al, 2002)

The resting surface electrocardiogram (ECG) is important in the initial evaluation of the patient for two reasons. First, it provides a screening tool to assess for remote infarctions (Ammar et al 2004; Michael et al, 2007), with changes such as pathological $Q$ waves, and other 
non-specific ST segment and T wave changes. Second, any such changes may guide the choice of the appropriate functional study. The presence of a left bundle branch block, for example, essentially renders exercise stress electrocardiography uninterpretable and confounds assessment of stress echocardiography or perfusion studies (La Canna et al, 1992).

Non-invasive tests such as exercise or pharmacological stress studies form an important pathway in the diagnostic algorithm. The value of a functional study cannot be overemphasized in patients with atypical or noncardiac chest pains. A negative functional study, such a negative treadmill test to 12 minutes on the Bruce protocol, provides sufficient prognostic information to negate any further investigations (Myers et al 2002; Marshall et al, 2010). The ischaemic burden as determined from imaging tests also provides pertinent guidance as to the appropriateness of revascularization. A substudy (Shaw et al 2008) of the COURAGE trial (Boden et al, 2007), which showed no benefit of PCI over optimized medical therapy, did show mortality and MI benefit with revascularizing patients with $>10 \%$ ischaemic myocardial burden. A well executed functional study may also assist in localizing the appropriate territory for revascularization, especially in the setting of multivessel intermediate lesions.

Patients with positive stress tests, especially with high risk features (table three), suggestive of significant ischaemic burden, should proceed to coronary angiography for risk stratification with a view to possible percutaneous or surgical revascularization. Indeed, of the indications of coronary angiography outlined in the ACC guideline for stable angina, a positive stress test with high risk features carries the highest level of evidence (Level A) compared to all other indications (level B to C).

Noninvasive test results predicting high risk for adverse outcome ( $>3 \%$ annual mortality rate)

Severe resting left ventricular dysfunction (LVEF <35\%)

High-risk treadmill score (score $\leq-11)$

Severe exercise induced left ventricular dysfunction (exercise LVEF <35\%)

Stress-induced large perfusion defect (particularly if anterior)

Stress-induced moderate-size multiple perfusion defects

Large, fixed perfusion defect with left ventricular dilatation or increased lung uptake

Stress-induced moderate-size perfusion defect with left-ventricular dilatation or increased lung uptake

Echocardiographic wall motion abnormality (involving $>2$ segments) developing at low dose of dobutamine $(\leq 10 \mathrm{mg} / \mathrm{kg} / \mathrm{min})$ or at a low heart rate $(<120 \mathrm{bpm})$

Stress echocardiographic evidence of extensive ischaemia

Table 3. High risk features in noninvasive tests

In some patients, however, it may be appropriate to consider coronary angiography as the initial investigation to confirm coronary artery disease. Patients who are symptomatic despite adequate or maximal antianginal therapy should proceed to coronary angiography 
with a view to revascularization for symptomatic benefit. As outlined in the ESC guideline on myocardial revascularization (Wijns et al, 2010), patients deemed to have a high pretest probability of coronary disease are advised against (IIIA and IIIB recommendations) noninvasive tests but to proceed to coronary angiography (IA recommendation). Patients intolerant of non-invasive testings, or with left ventricular dysfunction, could be considered for coronary angiography. Cardiac transplant patients continue to form an important group of the patients in whom coronary angiography is routinely performed for follow up for transplant vasculopathy. It continues to be a class II recommendation for patients awaiting organ transplant aged 40 years or older.

\subsubsection{Coronary artery disease - stable pattern - known coronary artery disease}

There is no role for surveillance routine coronary angiography in stable asymptomatic patients with known CAD, previous coronary interventions or coronary bypass surgery, unless as part of a research protocol. Patients who have documented coronary artery disease and previous interventions or CABG, who have developed recurred or worsening symptoms, coronary angiography is indicated and may be combined with percutaneous revascularization. It is reasonable to proceed to coronary angiography directly in these patients. Whilst functional non-invasive tests will still provide localizing data for inducible ischaemia, intravascular testing modalities such as intravascular ultrasound, optical coherence tomography and fractional flow reserve testing allow a robust evidence based approach to guide any revascularization (Tonino et al 2009; Pijls et al 2007).

\subsection{Coronary artery disease - unstable pattern}

\subsubsection{Acute coronary syndromes - with haemodynamic instability or rhythm} disturbance

Patients who presented with acute coronary syndromes with clinical instability (table 4) should proceed to urgent angiography with a view to possible revascularization (Hochman et al, 2006) either percutaneously or surgically if indicated.

Clinical instability in acute coronary syndromes

Cardiogenic shock

haemodynamic instability - severe hypotension on ischaemia

Recurrent/Persistent ischaemia and/or chest pain

Instability in cardiac rhythm e.g. major ventricular arrhythmia

Table 4. Clinical instability in acute coronary syndromes

\subsubsection{Acute coronary syndromes - unstable angina and non ST elevation acute coronary syndromes (non STEACS)}

Non STEACS is the most frequent presentation of acute coronary syndromes and carries at least as poor an outcome as STEACS (Chan et al 2009, Polonski et al, 2010). It is recommended (ESC and ACC class I recommendation) that patients who presented with non STEACS should be treated with an invasive strategy of coronary angiography. This is especially for patients with evidence of ischaemia on ECG or biomarkers, the two most 
powerful predictors of adverse events, as a prelude to definitive treatment for unstable coronary culprit lesions. Several meta-analyses including a Cochrane review (Hoenig et al, 2006; Fox et al, 2010; Mehta et al, 2005) of randomized controlled trials have concluded a routine invasive strategy improved ischaemic endpoints - reducing recurrent ischaemia, rehospitalisation and revascularization; and a more recent meta-analysis of three RCTs (FRISC-II, ICTUS, RITA-3) in 2010 (Fox et al, 2010) showed the benefit of a routine invasive strategy in cardiovascular death or non fatal MI was maintained at five years. Whilst the meta-analysis was conclusive, one must note the heterogeneity in the trials included. The most controversial trial, published in 2005, comparing a routine invasive vs. conservative strategy, ICTUS (de Winter et al, 2005), was the only trial to show no difference in the ischaemic end points between the two strategies. Five year follow up data from this study continued to show no long-term benefit of an early invasive strategy in reducing death or MI (Damman et al, 2010). Notably, 54\% of the initially conservatively treated patients received revascularization within one year. It is likely the ability of the ICTUS trial to demonstrate difference in clinical outcomes has been significantly compromised by the cross over rate (Cannon, 2004) from medical therapy to invasive treatment.

As a result of the heterogeneity between trials (inclusion criteria, definitions of MI, intensity of pharmacological treatment and frequency of revascularization) and the confounding results, this issue of routine invasive vs. conservative treatment strategy continues to spurn passionate debate (Bittl \& Maron, 2010; Thompson, 2010). The 2011 ACC guidelines (Anderson et al, 2011) acknowledge that in selective patients without high-risk features who have been stabilized, an initially conservative strategy may not be inappropriate, especially those with serious co morbidities or contraindications to angiography and intervention who have an elevated risk for clinical events, for example, patients with advanced malignancy and a history of contrast allergy who declines invasive procedures. The decision to avoid angiography in these patients may be made by considering the clinical evaluation of the physician and patient preference. It is those patients enjoying satisfactory quality of life who demonstrate the highest clinical risk profile that derive the most benefit and should receive an early invasive strategy.

When an early invasive approach has been decided for a patient, the exact timing to invasive coronary angiography is not very well established and subject to ongoing research. This of course differs from the management in STEACS where urgent reperfusion is vital. Various trials have attempted to answer the question of timing of coronary angiography in NSTEACS. The risk of adverse cardiovascular events is time dependant. These events in the unstable patient group are more common in the early phase after initial clinical presentation. An early invasive treatment may prevent impending reinfarction or ischaemia, but the counterargument is that an adequate pre procedural period of pharmacotherapy may "prepare" the lesion better to minimize complications such as no reflow. The data is not definitive. Small trials (Neumann et al, 2003), non-clinical primary endpoints (Montalescot et al, 2009), possibly underpowered studies (Mehta et al, 2009) are all factors that make definitive evidence based recommendations difficult.

Whilst the evidence differs between various trials, it is reasonable the low to intermediate risk NSTEACS patients undergo coronary angiography within 72 hours. This is reflected in the conservative arm of recent studies in whom a delayed approach is now considered a median of 24 hours after the onset of symptoms compared to 72 hours 10 years ago. Based on subgroup analysis on the TIMACS study in which patients with a GRACE score $>140$ 
benefited most from an early invasive strategy, this group of high risk patients would benefit from prompt (<24 hours) coronary angiography.

\begin{tabular}{|c|c|c|c|c|c|c|}
\hline & Patients & Study design & $\begin{array}{l}\text { Median } \\
\text { early vs. } \\
\text { Late } \\
\text { difference } \\
\text { (hrs) }\end{array}$ & $\begin{array}{l}\text { Primary } \\
\text { endpoint }\end{array}$ & Results & Other findings \\
\hline $\begin{array}{l}\text { TACTICS } \\
\text { TIMI } 18 \\
(2001)\end{array}$ & NSTEACS & $\begin{array}{l}\text { Angiography } \\
4-48 \text { vs. } \\
\text { selective } \\
\text { invasive }\end{array}$ & $\begin{array}{l}22 \mathrm{hrs} \text { vs. } \\
79 \mathrm{hrs}\end{array}$ & $\begin{array}{l}6 \text { month death, } \\
\text { MI, } \\
\text { rehospitalization } \\
\text { for MI }\end{array}$ & $\begin{array}{l}15.9 \% \text { vs. } \\
19.4 \% \\
(p=0.025)\end{array}$ & \\
\hline $\begin{array}{l}\text { ISAR- } \\
\text { COOL } \\
(2003)\end{array}$ & NSTEACS & $\begin{array}{l}\text { Angiography } \\
<6 \text { hrs vs. }> \\
72 \text { hrs }\end{array}$ & $\begin{array}{l}2.4 \text { hrs vs. } \\
86 \text { hrs }\end{array}$ & $\begin{array}{l}30 \text { day death or } \\
\text { large MI }\end{array}$ & $\begin{array}{l}5.9 \% \text { vs. } \\
11.6 \% \\
(p=0.04)\end{array}$ & \\
\hline $\begin{array}{l}\text { TIMACS } \\
\text { (2009) }\end{array}$ & $\begin{array}{l}\text { NSTEACS, } \\
<24 \text { hrs of } \\
\text { pain }\end{array}$ & $\begin{array}{l}\text { Angiography } \\
<24 \text { hrs vs. } \\
>36 \text { hrs after } \\
\text { randomization }\end{array}$ & $\begin{array}{l}14 \text { hrs vs. } \\
50 \text { hrs }\end{array}$ & $\begin{array}{l}6 \text { month death, } \\
\text { MI, stroke }\end{array}$ & $\begin{array}{l}9.6 \% \text { vs. } \\
11.3 \% \\
(p=0.15)\end{array}$ & $\begin{array}{l}\text { Refractory } \\
\text { ischaemia } 3.3 \% \\
\text { vs. } 1.0 \% \\
(p<0.001) \\
\end{array}$ \\
\hline $\begin{array}{l}\text { ABOARD } \\
(2009)\end{array}$ & NSTEACS & $\begin{array}{l}\text { Angiography } \\
\text { "immediate" } \\
\text { vs. delayed }\end{array}$ & $\begin{array}{l}70 \mathrm{~min} \\
\text { vs. } 21 \mathrm{hrs}\end{array}$ & $\begin{array}{l}\text { Peak troponin I } \\
\text { during } \\
\text { hospitalization }\end{array}$ & $\begin{array}{l}2.1 \mathrm{vs} . \\
1.7 \\
\mathrm{ng} / \mathrm{mL}\end{array}$ & $\begin{array}{l}2^{0} \text { death, } \mathrm{MI}, \\
\text { urgent } \\
\text { revascularization } \\
13.7 \% \text { vs. } 10.2 \% \\
\mathrm{p}=0.31\end{array}$ \\
\hline
\end{tabular}

Table 5. Timing of coronary angiography in NSTEACS

\subsubsection{Acute coronary syndromes - ST elevation ACS}

The cornerstone of management in ST elevation ACS is the timely restoration of flow in the infarct related artery. The accepted strategies for reperfusion include primary PCI and thrombolysis. If available within a timely fashion from an experienced team, urgent coronary angiography and primary PCI offers better patient outcomes than thrombolysis in STEACS. In addition, primary PCI is recommended in patients with cardiogenic shock or contraindication to thrombolysis.

In patients with failed thrombolysis, or recurrent ischaemia after initially successful thrombolysis, urgent coronary angiography should be considered, as shown in a metaanalysis in 2007 (Wijeysundera et al, 2007). Rescue PCI is associated with significant risk reduction in reinfarction and heart failure, as well as a trend towards mortality reduction. In the REACT trial (Gerschlick et al, 2005), there was a significant reduction of the primary composite end point of death, reinfarction, stroke or severe heart failure at six months for rescue PCI, compared to both conservative treatment of repeat thrombolysis. Long term data (Carver et al, 2009), median 4.4 years, from this trial reinforced the mortality reduction of rescue PCI over both conservative treatment or repeat thrombolysis (RR 0.41, $\mathrm{p}=0.004$; RR $0.43, \mathrm{p}=0.006$, respectively). Repeat thrombolysis is contraindicated. It is associated with excessive bleeding and no benefit in reperfusion. In patients who presented to a non PCIcapable centre, if transfer to a PCI-capable centre can be undertaken such that the delay between first medical contact and balloon inflation is less than two hours, patient should be 
transferred to the PCI-capable centre. Established logistics and personnel arrangement must be in place for this to take place.

In patients with successful thrombolysis, the timing of transfer to a PCI-capable facility and the timing of angiography have been addressed in several contemporary trials and metaanalyses. Several recent meta-analyses (Borgia et al, 2010; Desch et al, 2008; Savio et al, 2010) which included studies such as CARESS-AMI (Di Mario et al, 2009), TRANSFER-AMI (Cantor et al, 2010) and NORDISTEMI (Bøhmer et al, 2009), demonstrated that early transfer to a PCI capable facility is associated with a significant reduction in the combined endpoint of 30 day mortality, re-infarction, ischaemia. The benefit appears to be driven most by a reduction of re-infarction and ischaemia. Current ESC and ACC guidelines recommend this pharmacoinvasive strategy, or "drip and ship" strategy, the prompt transfer of thrombolyzed patients to a PCI capable hospital within 24 hours.

The timing of coronary angiography deserves special mention. In stable patients successfully thrombolyzed, having been transferred to a PCI capable facility, coronary angiography and PCI should be deferred until 3 to 24 hours after thrombolysis. Whilst immediate coronary angiography appears attractive a proposition, evidence from "facilitated PCI" suggests otherwise. Facilitated PCI is a strategy of immediate angiography and PCI after pharmacotherapy such as upstream full or half dose thrombolytic therapy, with or without glycoprotein IIb/IIIa inhibitor. Several trials have addressed this question. ASSENT-4 (ASSENT-4 investigators, 2006), assessing tenecteplase then PCI compared to primary $\mathrm{PCI}$, showed increased rates of ischaemic and bleeding complications with facilitated PCI, and FINESSE (Ellis et al, 2008, reduced reteplace and abciximab then PCI vs. abciximab then PCI vs. PCI) showed no difference in the mortality, ventricular function or cardiogenic shock but excess bleeding. A meta-analysis (Keeley et al, 2006) of 18 trials over 3 decades showed no benefit of facilitated PCI over primary PCI. There is currently no data to recommend the use of "facilitated" PCI. Pharmacoinvasive strategy is encouraged but facilitated PCI is not.

Coronary angiography should be performed prior to definitive surgical treatment for mechanical complications of any myocardial infarction (e.g. ventricular septal defect, acute mitral regurgitation or ventricular aneurysm). There are some situation however where the delays associated with angiography may outweigh the benefits of defining the coronary anatomy. For example angiography should not delay emergent surgical treatment of VSD and shock or aortic dissection.

\subsubsection{Out of hospital cardiac arrest (OOHCA)}

Patients who have survived an out of hospital cardiac arrest with return of spontaneous circulation (ROSC) may or may not present with diagnostic ischaemic ECG changes. In patients with definitive changes such as ST elevation, they should be treated as outlined above with an immediate invasive strategy. In haemodynamically and rhythmically stable patients after cardiac arrest, the appropriate timing (immediate vs. deferred) of coronary angiography is the subject of particular interest. Up to $80 \%$ of OOHCA patients have had an acute coronary syndrome as the precipitant (Pell et al, 2003) and ECG changes are not necessarily predictive (Aurore et al, 2011). Given this finding, it was not surprising some studies (Dumas et al, 2010; Reynolds et al, 2009; Spaulding et al, 1997; Sunde et al, 2007; Stub et al 2010) have shown an improved outcome, including cardiac ejection fraction, 


\begin{tabular}{|c|c|c|c|c|c|c|}
\hline & Patients & Study design & $\begin{array}{l}\text { Primary } \\
\text { endpoints }\end{array}$ & Results & $\begin{array}{l}\text { Hrs to PCI } \\
\text { in transfer } \\
\text { group }\end{array}$ & $\begin{array}{l}\text { Other } \\
\text { findings }\end{array}$ \\
\hline $\begin{array}{l}\text { CARESS-in- } \\
\text { AMI (2008) }\end{array}$ & $\begin{array}{l}75 \text { y.o. or } \\
\text { younger } \\
\text { STEACS, 1/2 } \\
\text { reteplace } \\
\text { with } \\
\text { abciximab, } \\
\text { heparin, } \\
\text { aspirin } \\
\text { within } 12 \\
\text { hours of } \\
\text { pain }\end{array}$ & $\begin{array}{l}\text { Immediate } \\
\text { transfer for } \\
\text { angiography } \\
\pm \text { PCI vs. } \\
\text { standard } \\
\text { treatment } \\
\text { (with transfer } \\
\text { for rescue if } \\
\text { needed) }\end{array}$ & $\begin{array}{l}30 \text { day } \\
\text { death, } \\
\text { reinfarction, } \\
\text { refractory } \\
\text { ischaemia }\end{array}$ & $\begin{array}{l}\text { RR } 0.40 \\
(p=0.004)\end{array}$ & $\begin{array}{l}<3 \\
\text { (median 2.2) }\end{array}$ & \\
\hline $\begin{array}{l}\text { TRANSFER- } \\
\text { AMI (2009) }\end{array}$ & $\begin{array}{l}\text { STEACS, } \\
\text { tenecteplase } \\
\text { within } 12 \\
\text { hours of } \\
\text { pain }\end{array}$ & $\begin{array}{l}\text { Immediate } \\
\text { transfer for } \\
\text { angiography } \pm \\
\text { PCI within } 6 \\
\text { hours vs. } \\
\text { standard- } \\
\text { treatment } \\
\text { (deferred > } \\
24 \text { hrs) }\end{array}$ & $\begin{array}{l}30 \text { day } \\
\text { death, } \\
\text { reinfarction, } \\
\text { recurrent } \\
\text { ischaemia, } \\
\text { new CCF, } \\
\text { cardiogenic } \\
\text { shock }\end{array}$ & $\begin{array}{l}\text { RR } 0.64 \\
(p=0.004)\end{array}$ & $\begin{array}{l}<6 \\
(\text { median } 3.9)\end{array}$ & \\
\hline $\begin{array}{l}\text { NORDISTEMI } \\
(2010)\end{array}$ & $\begin{array}{l}75 \text { y.o. or } \\
\text { younger, } \\
\text { STEACS, } \\
\text { teneteplase } \\
<6 \mathrm{hr} \text { of } \\
\text { pain, } \\
\text { tenecteplase }\end{array}$ & $\begin{array}{l}\text { Immediate } \\
\text { angiography } \\
\pm \text { PCI vs. } \\
\text { Deferred }\end{array}$ & $\begin{array}{l}12 \text { month } \\
\text { death, } \\
\text { reinfarction, } \\
\text { stroke, new } \\
\text { ischaemia }\end{array}$ & $\begin{array}{l}\text { RR } 0.72 \\
\text { (NS) }\end{array}$ & $\begin{array}{l}\text { As soon as } \\
\text { possible } \\
\text { (median 2.7) }\end{array}$ & $\begin{array}{l}30 \text { day } \\
\text { death, } \\
\text { reinfarction, } \\
\text { stroke or } \\
\text { new } \\
\text { ischaemia } \\
\text { (RR } 0.49 \\
\text { p }=0.03 \text { ) }\end{array}$ \\
\hline
\end{tabular}

Table 6. Timing of transfer of STEACS patients to a PCI capable facility

neurological recovery and survival, with this strategy. The largest study of this patient group is the PROCAT registry (Dumas et al, 2010) from Paris suggested that immediate angiography and successful PCI improved survival (odds ratio 2.06, p=0.013). Given the evidence leading centers have adoped a strategy of immediate coronary angiography and revascularisation as indicated after an OOHCA with ROSC. Indeed, this is the recommendation endorsed by the International Liaison Committee on Resuscitation (ILCOR, 2010) but the level of evidence is relatively low. Coma or significant neurological compromise are common in this patient group and these should not preclude consideration of angiography with full neurological recovery in initially comatose STEACS patients found in various registries (Garot et al, 2007; Hosmane et al, 2009). Further, the induction of 
hypothermia (Bernard et al, 2002; Wolfrum et al, 2008) should be incorporated as part of the treatment strategy for those undergoing immediate angiography.

\subsection{Special considerations}

\subsubsection{Congestive cardiac failure}

Invasive coronary angiography is useful in the investigation of left ventricular systolic dysfunction for an ischemic aetiology, especially in the presence of suggestive features such as angina, remote history of severe angina or even silent infarction, ischaemia on surface electrocardiogram, or regional wall motion abnormalities on cardiac imaging. Since the 1999 ACC guideline, the advance of non-invasive computed tomography coronary angiography (Andreini et al, 2009), with its high sensitivity and negative predictive value, may justify its use for this particular indication rather than invasive coronary angiography. The negative predictive value of a normal scan has been shown to approach $100 \%$.

\subsubsection{Preoperative assessment for noncardiac surgery}

The premise of preoperative cardiac, in particular coronary, assessment for noncardiac surgery is to prevent peri operative cardiac adverse events and mortality. Surgery places significant physiological stresses that may cause cardiac ischaemia from stenosed epicardial arteries as well as inflammation and activation of the coagulation cascade possibly precipitating acute coronary syndromes.

As a general rule, the patient should be managed as would be in a non-surgical setting and testing of any type should only be undertaken if it is likely to change peri operative management. As such, in any emergency life saving operations, it is accepted any cardiac investigations should not be performed.

Coronary angiography has a limited role in the routine management of patients planned for non-cardiac surgery. A comprehensive discussion on the preoperative assessment of noncardiac surgery is beyond the scope of this chapter but the key determinants are: patient symptoms and clinical risk profile, surgical risk estimate (table 7) (Boersma et al, 2005), and the patient's functional capacity.

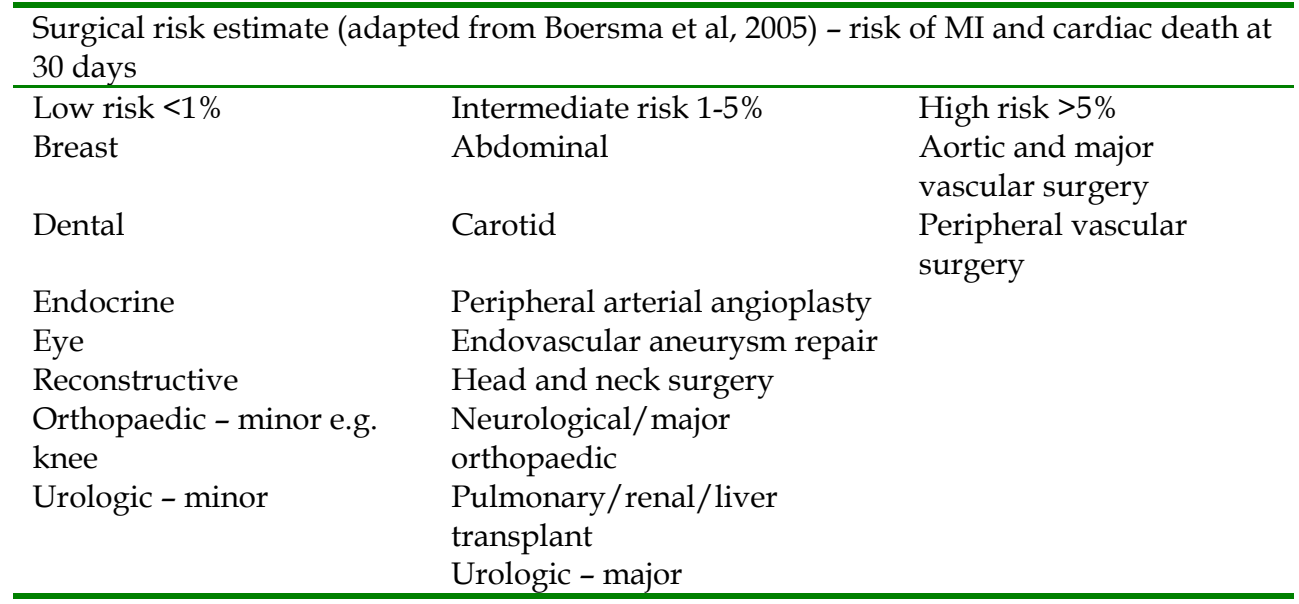

Table 7. Risk of adverse cardiac events in different surgical scenarios 
Patients who have stable angina or are asymptomatic can generally proceed with surgery. Patients who have worsening symptoms of ischaemia probably deserve further assessment, namely in the form of functional studies, prior to elective surgery. The same indications for coronary angiography and/or intervention should apply here as would be in the nonsurgical setting. The cardiac risks of the particular operation should be assessed. It is a class I recommendation (Poldermans et al, 2009) that pre-operative coronary angiography be performed in acute coronary syndromes as well as in patients with angina refractory to medical therapy. Pre-operative angiography is not recommended in cardiac-stable patients undergoing low-risk and even intermediate risk surgery.

Evidence of improved outcome with revascularization prior to surgery however is lacking. There is little data pertaining to the benefit of revascularization in patients undergoing non cardiac vascular surgery, a subset of surgical patients known for high cardiac co-morbidity. One study (McFalls et al, 2004 - Coronary Artery Revascularization Prophylaxis CARP study) on stable CAD patients with preserved LV failed to demonstrate improved outcome with prophylactic revascularization compared to optimized medical therapy. Another study (Poldermans et al, 2007 - DECREASE-V pilot study), assessed the same concept on complex CAD with impaired LV systolic function, and reached the same conclusion. This was despite $75 \%$ of these cases having three vessel or left main coronary artery disease. On the currently limited available data, prophylactic revascularization cannot be recommended.

\subsubsection{Non invasive computed tomography coronary angiography (CTCA)}

Over the past decade the technological advances in CTCA have meant that the technology is emerging as an important investigation in a range of clinical scenarios. Aside from its noninvasive nature, CTCA provides information about both vessel lumen and important information on the composition of plaque and the vessel wall as well as other cardiac structures. However, it is important to note the spatial and temporal resolutions remain inferior to invasive coronary angiography with the current technology. Various multicentre studies (Budoff et al, 2008; Miller et al, 2008; Mowatt et al, 2008) on 64 slice CTCA have been published and confirmed its inferiority to invasive coronary angiography particularly in its specificity and the limitation on small vessel definition (table 8). The evidence for its clinical application continues to evolve.

\begin{tabular}{lllllll}
\hline $\begin{array}{l}\text { Study } \\
\text { author }\end{array}$ & $\begin{array}{l}\text { Sensitivity } \\
\text { per vessel }\end{array}$ & $\begin{array}{l}\text { Specificity } \\
\text { per vessel }\end{array}$ & $\begin{array}{l}\text { Sensitivity } \\
\text { per patient }\end{array}$ & $\begin{array}{l}\text { Specificity } \\
\text { per } \\
\text { patient }\end{array}$ & $\begin{array}{l}\text { Negative } \\
\text { predictive } \\
\text { value } \\
\text { (per atient) }\end{array}$ & $\begin{array}{l}\text { Positive } \\
\text { predictive } \\
\text { value } \\
\text { (per patient) }\end{array}$ \\
\hline $\begin{array}{l}\text { Budoff et al 84\% } \\
2008\end{array}$ & $90 \%$ & $95 \%$ & $83 \%$ & $99 \%$ & $64 \%$ \\
$\begin{array}{l}\text { Meijboom } \\
\text { et al 2008 }\end{array}$ & $75 \%$ & $99 \%$ & $64 \%$ & $97 \%$ & $86 \%$ \\
$\begin{array}{l}\text { Miller et al } \\
\text { 2008 }\end{array}$ & $93 \%$ & $85 \%$ & $90 \%$ & $83 \%$ & $91 \%$ \\
\hline
\end{tabular}

Table 8. Meta-analyses of accuracy 64 slice CTCA compared to coronary angiography 
Guidelines on the appropriateness of CTCA (Taylor et al, 2010) published in 2010 attempted to address the use of this rapidly evolving technology. The indications chosen mirrored that of invasive coronary angiography. In view of its high sensitivity, CTCA is particularly suited to low to intermediate risk patients in the setting of stable symptomatic patients, low risk acute coronary syndromes and heart failure patients. Patients with normal CTCA findings convey a very low risk of future cardiac events and cardiac mortality (Hulten et al, 2011). Patients at high risk of coronary artery disease are advised against CTCA as this represents hindrance to timely diagnosis and management of CAD with the additional risk of contrast and radiation. It has no role in the preoperative assessment of non-cardiac surgery. It is deemed appropriate in the assessment of graft patency for symptomatic patients with previous CABG. To reflect the emerging role of left main stenting, CTCA has been deemed appropriate as a means for routine follow up screening of left main stent(s) in asymptomatic patients.

Unless the limitations of CTCA can be sufficiently improved upon, it is likely CTCA will continue to be utilized in a complementary role to invasive coronary angiography in the assessment of CAD. Of course the major advantage of angiography remains the ability to proceed on to coronary intervention as part of the imaging procedure.

\subsection{Relative and absolute contraindications}

The only absolute contraindication is if a patient refuses the test fully understanding the risk and benefit of his/her decision, refuses any treatment for CAD regardless of the result of the coronary angiography, or if other medical co-morbidities rendering imaging of the coronaries and revascularization inappropriate or impossible. Subjecting the patient to even the small risks of a coronary angiogram with no foreseeable gain cannot be justified. Relative contraindications include situations which increase the likelihood of complications, e.g. bleeding diathesis, coagulopathy (iatrogenic i.e. warfarin or pathological), renal impairment, anaemia, contrast allergy, active infection and aortic valve vegetation. If these relative contraindications are reversible the patient should be appropriately prepared and coronary angiography deferred.

\section{Valvular heart disease and structural heart disease intervention}

The assessment of the coronary anatomy prior to cardiac valvular surgery is routine although not necessarily evidence driven. Whilst surgery for valvular heart disease has been performed for many years, percutaneous intervention for structural or valvular heart disease has been generating significant interest over the recent years. Transcatheter aortic valve implants (TAVI) have already demonstrated significant mortality benefit in patients deemed unsuitable for surgery compared to medical therapy, in the first RCT on TAVI (PARTNERS trial) (Leon et al, 2010). Several investigational percutaneous treatment options also exist for mitral regurgitation. Percutaneous coronary revascularization has been a prerequisite for the TAVI procedures and as such all patients underwent coronary angiography. The incidence of coronary disease in this patient group is high, up to $70 \%$ the PARTNERS trial. Coronary angiography is a pivotal part in the assessment for TAVI suitability. The increasing percutaneous treatment options will likely generate in the future specific college endorsed guideline to incorporate the role of coronary angiography in pre structural heart intervention.. 


\subsection{Pre valvular surgery}

It is routine to perform coronary angiography prior to valve surgery although there is no evidence to guide such practice (Bonow et al, 2006; Vahanian et al, 2007). This is especially logical in older patients with cardiac risk factors, or suggestion of CAD from symptoms, ECG, cardiac imaging or non-invasive function studies. The indication is less clear in younger patients, and special caution must be exercised in aortic valve surgery for infective endocarditis given the risk for vegetation embolization. No definitive data are available to define the clinical benefit of revascularization in the setting of corrective valve surgery. Whilst it is reasonable to expect benefit in prognostic disease, the same generalization may not apply to single vessel non prognostic lesions which would otherwise not necessarily be revascularized in a non-surgical setting. The role of CTCA is yet to be defined but its application here may reasonably mimic that outlined previously, in a low to intermediate risk group of patients undergoing valvular surgery (Meijboom et al, 2006).

\subsubsection{Pre percutaneous valve implant}

This is a developing area in which the role of coronary angiography appears crucial. Coronary angiography and if necessary percutaneous revascularization were a requisite for all TAVI trials so as to allow for direct comparison with the CABG + AVR subgroup. It seems nonetheless reasonable for this group of high risk patients, often with symptoms indistinguishable from ischaemia, to undergo coronary angiography. In addition, the left heart catheterization is pivotal for necessary measurement of aortic dimensions, angulation, coronary ostia position and origin, and assessment of vascular access. It should be noted the indication of revascularization in patients undergoing TAVI stems from its equivalent in surgical treatment, the exact timing and completeness of revascularization are yet to be defined.

The more difficult question relates to the need for coronary angiography in patients who may not otherwise meet the indications for coronary angiography, e.g. pulmonary valve implant in a young congenital heart disease patient, mitral valve clip in severe functional mitral regurgitation. These patients are managed the patient in a similar fashion to the conventional indications for coronary angiography.

\subsubsection{Other structural cardiac interventions}

There is limited evidence to support routine coronary angiography in structural cardiac interventions such as patent foramen ovale and atrial septal defect closure, coarctation stenting, patent ductus arteriosus interventions. It is often performed however based on the individual patient's clinical risk profile. The discovery of prognostically significant coronary artery disease not amenable to percutaneous coronary interventions may sway treatment towards a complete surgical treatment option. Coronary angiography does not increase the invasive nature of these procedures and add little incremental risk.

\section{Case vignettes of the use of coronary angiography in the contemporary era}

Case One - atrial septal defect with multi-vessel coronary artery disease

A 73 year old female presented with NYHA (New York Heart Association) class II exertional dyspnoea. Her cardiac risk factors included hypertension and hyperlipidaemia. A 
transthoracic echocardiogram demonstrated two small secundum atrial septal defects (ASD), with moderate right ventricular dilatation and normal systolic function. Percutaneous ASD closure was attempted. Coronary angiography was performed, especially given the uncharacteristically late presentation of her ASD, as well as her cardiac risk factors. This demonstrated prognostically significant triple vessel disease (Figure 1a, 1b, 2c), with an osital $90 \%$ left circumflex artery stenosis, $90 \%$ mid left anterior descending artery bifurcation stenosis and a $90 \%$ distal right coronary artery stenosis. Given the unfavourable percutaneous prospect for the coronary lesions, she was referred for surgical complete revascularization and ASD closure. She was discharged uneventfully one week after surgery. Coronary angiography should be considered prior to structural cardiac interventions in patients with cardiac risk factors and may alter management.

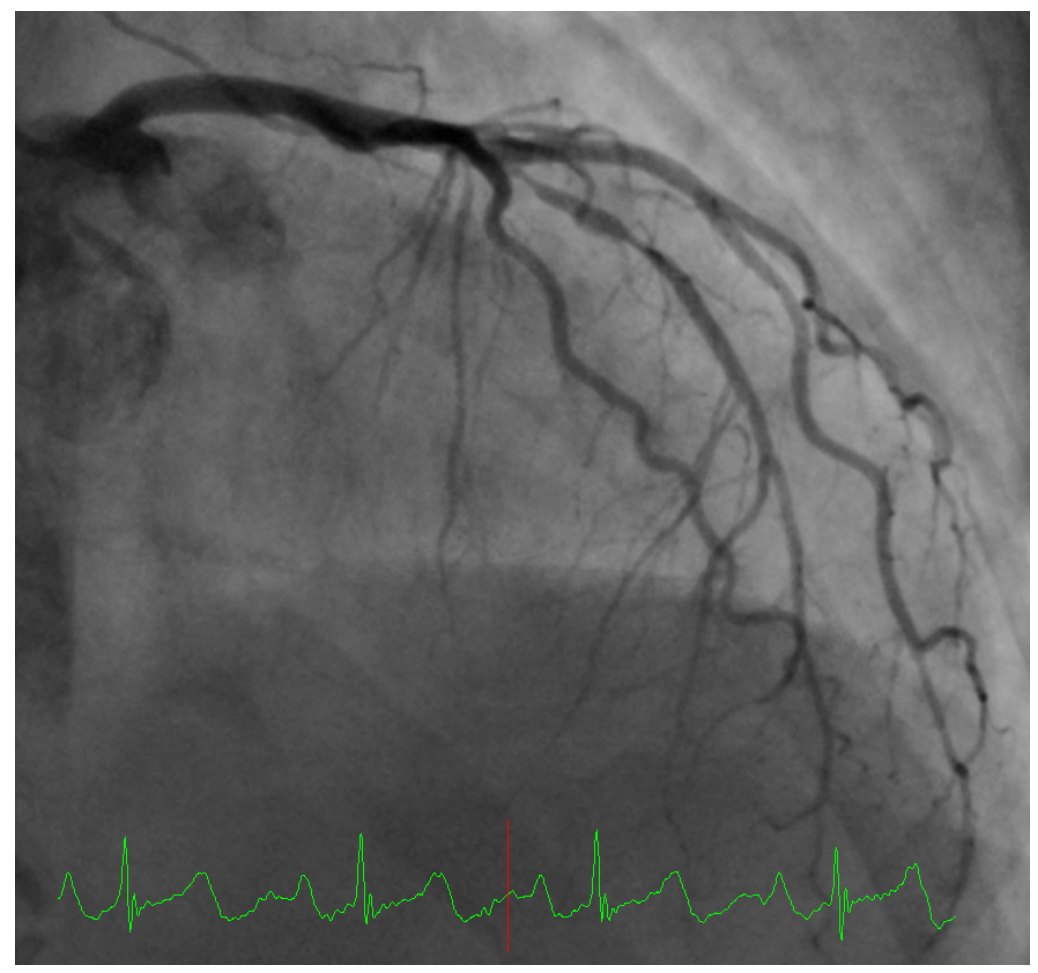

Fig. 1a. Left anterior artery stenoses 


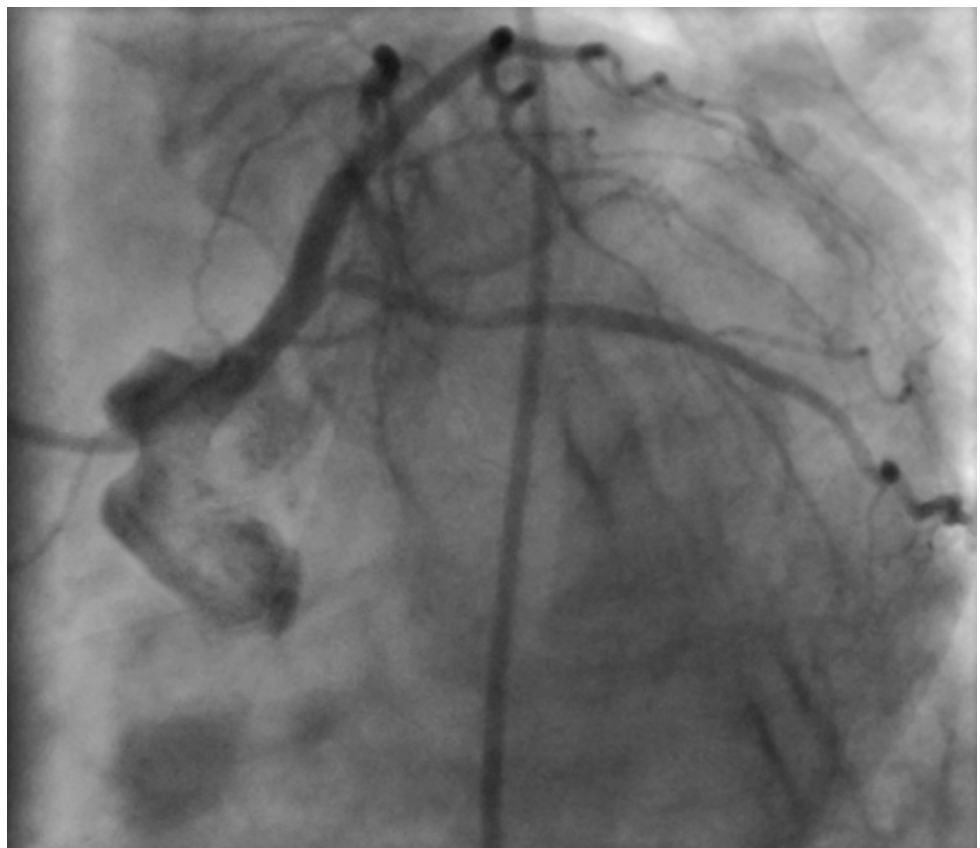

Fig. 1b. Ostial left circumflex stenosis

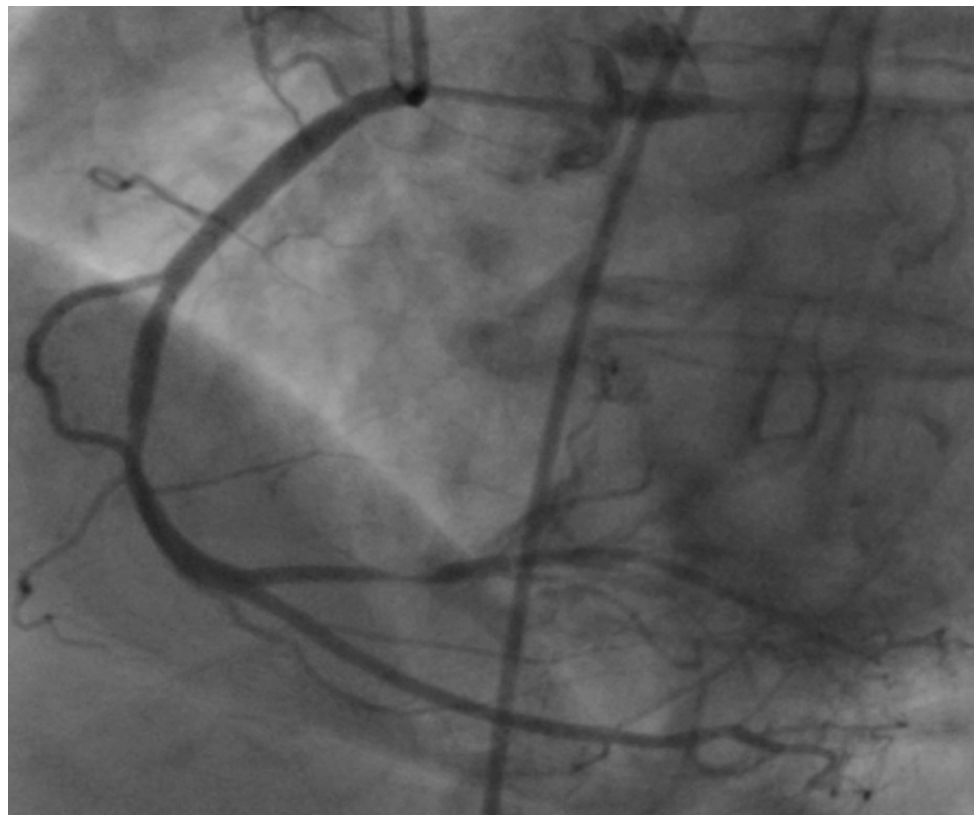

Fig. 1c. Posterolateral branch stenosis 
Case Two - post TAVI angiogram

An 84 year old male represented with angina two years after a successful transcatheter aortic valve implant (TAVI) with a bioprosthetic CoreValve ${ }^{\circledR}$. His NYHA symptomatology improved from Class IV to Class I. His coronary angiogram and graft study prior to his TAVI showed patent grafts (LIMA-LADD1-LAD; SVG-OM1; SVG-PDA) but severe native disease including a severely diseased grafted PDA with no prospect for surgical or percutaneous revascularization. A coronary angiogram and graft study was performed through his CoreValve ${ }^{\circledR}$ to assess if his underlying disease had progressed (Figure 2a).

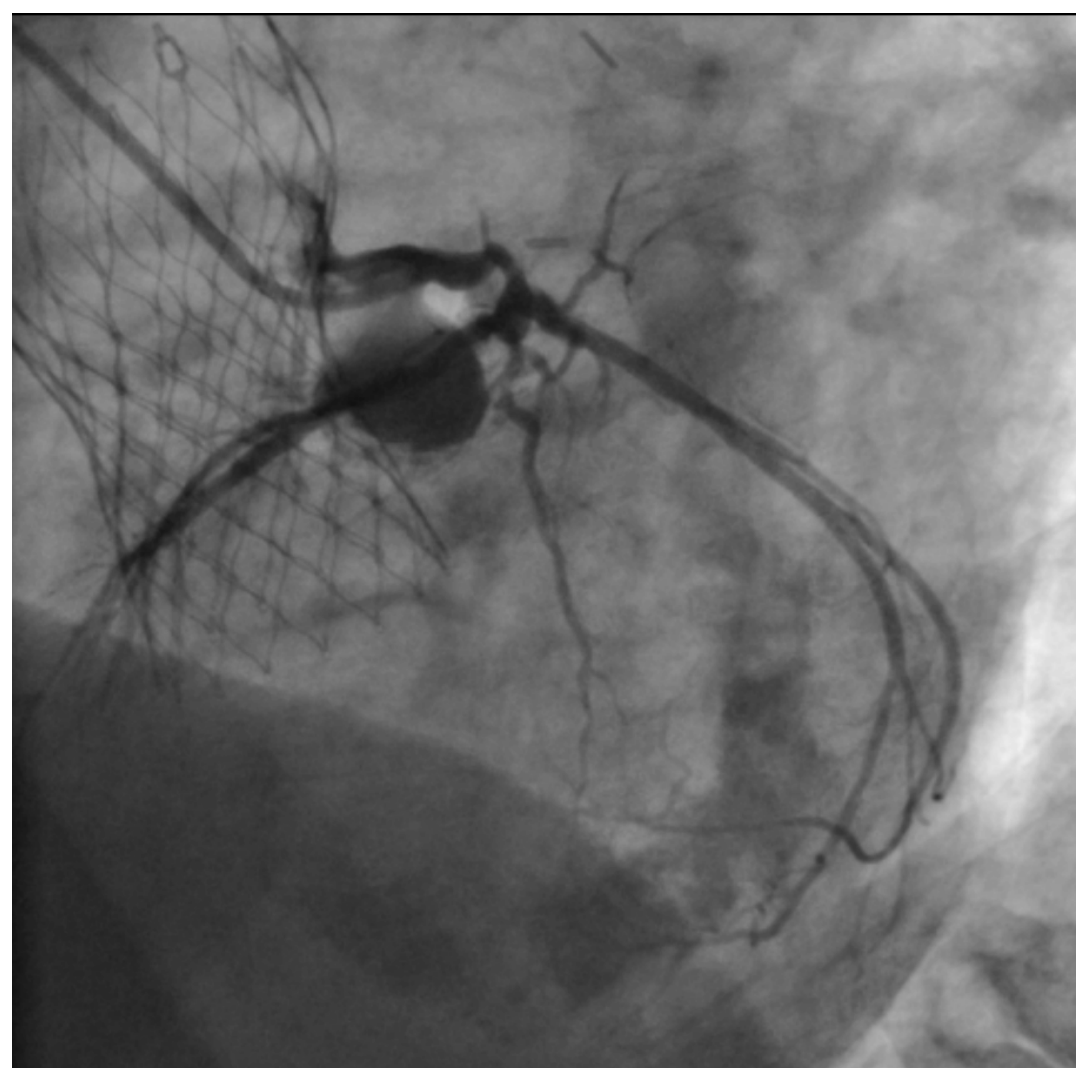

Fig. 2a. Angiography with a 5 French Judkins Left 5 catheter through a CoreValve ${ }^{\circledR}$ bioprosthesis 
This demonstrated patent grafts as previously noted but progression in his PDA disease (Figure $2 \mathrm{~b}$ ). Percutaneous, or surgical, treatment remained an unfavourable prospect and he was successfully treated with intensified medical therapy with CCS (Canadian Cardiovascular Society) I angina. Coronary angiography can be safely performed through CoreValve struts but care must be exercised with the choice and manipulation of catheters.

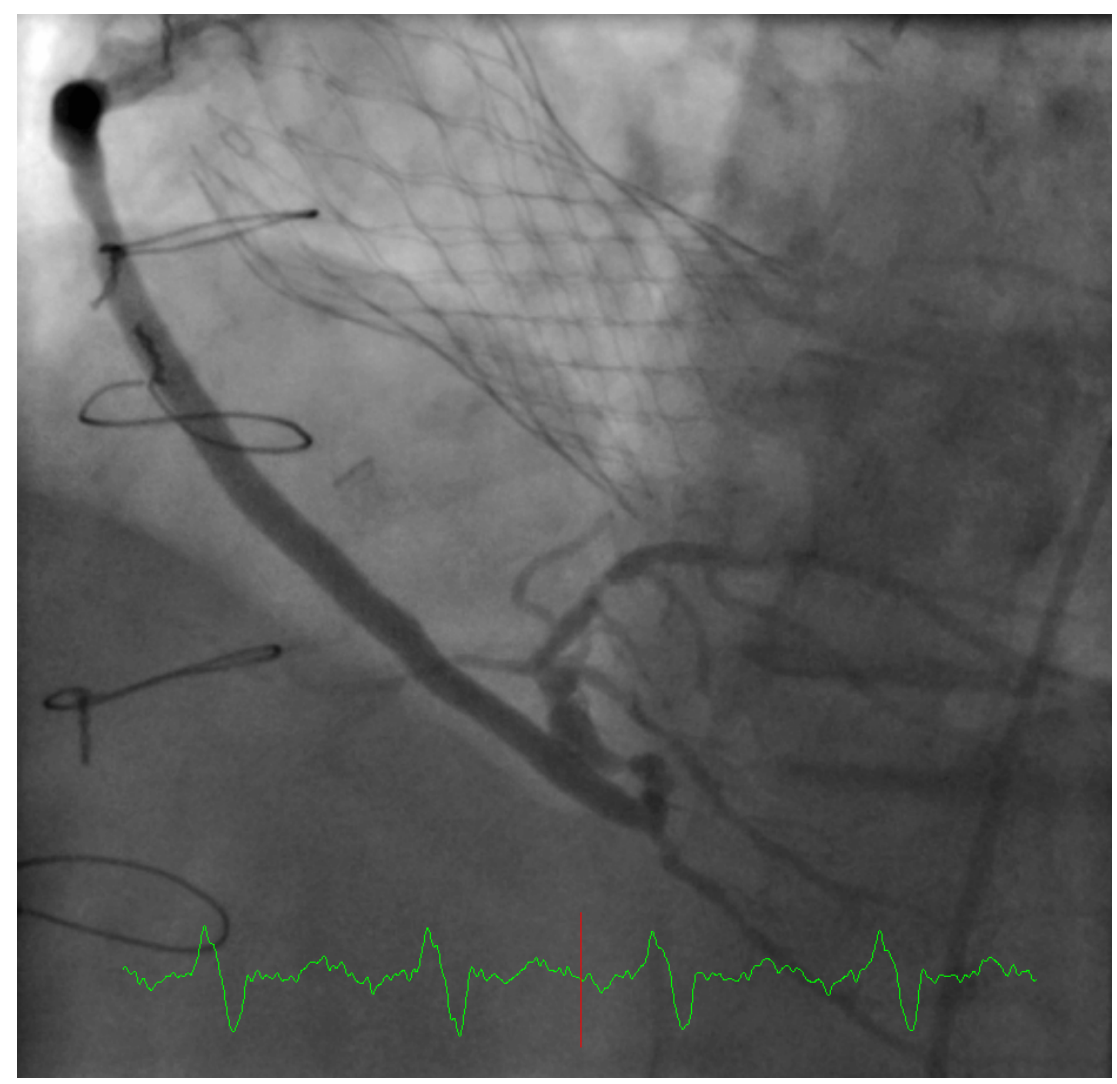

Fig. $2 b$. Severe native posterior descending artery disease not amenable to percutaneous treatment

Case Three - percutaneous treatment of left main stenosis and aortic stenosis

A 76 year old male with severe aortic stenosis was referred for possible percutaneous treatment due to his high surgical risk. Assessment for TAVI entailed a coronary angiogram, aortogram and an iliofemoral angiogram (Figure 3a). Coronary angiography revealed a significant left main stenosis (Figure $3 b$ ) which on intravascular ultrasound measured 5.8 mm2. A multidisciplinary heart team assessed the data and concluded surgical treatment to be prohibitively high risk. The patient then underwent left main stenting with a drug eluting stent under IVUS guidance. Satisfactory stent expansion was attained with a final diameter of $4.5 \mathrm{~mm}$ (Figure 3c). The patient then proceeded to a successful TAVI (CoreValve®) implant and continued to enjoy excellent symptom relief at six months. 
Coronary angiography, and arterial (aortic, iliac, and femoral) assessment, form an integral part of TAVI assessment. Elderly patients with severe aortic stenosis often have severe coexisting coronary artery disease as well as peripheral vascular disease as demonstrated by this case. Optimizations of the coronary status, as well as an appreciation of the peripheral vasculature, are absolutely paramount to a successful TAVI implant and to avoid vascular complications.

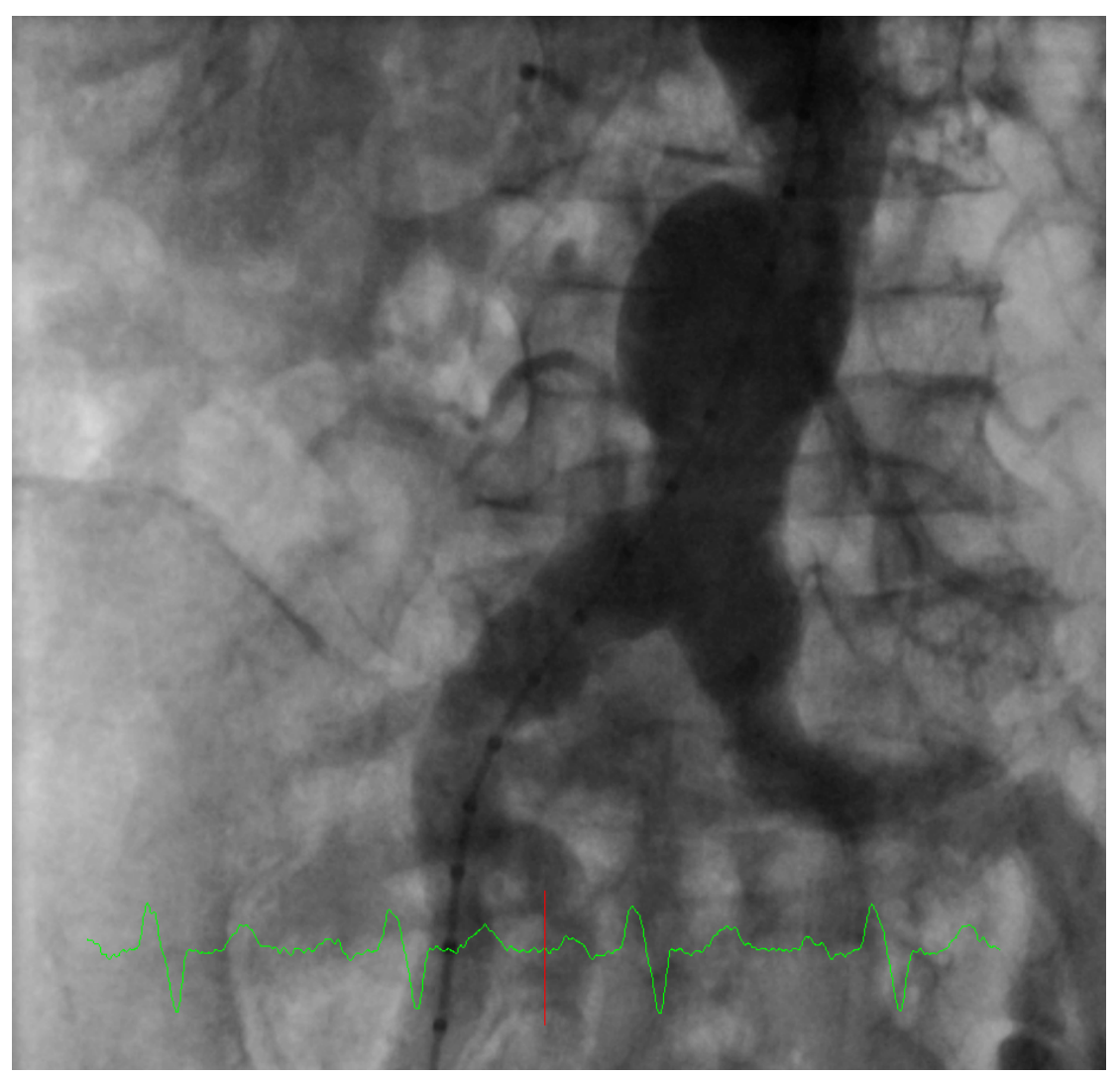

Fig. 3a. Tortuous aorta and iliac arteries, important information for TAVI transfemoral access. 


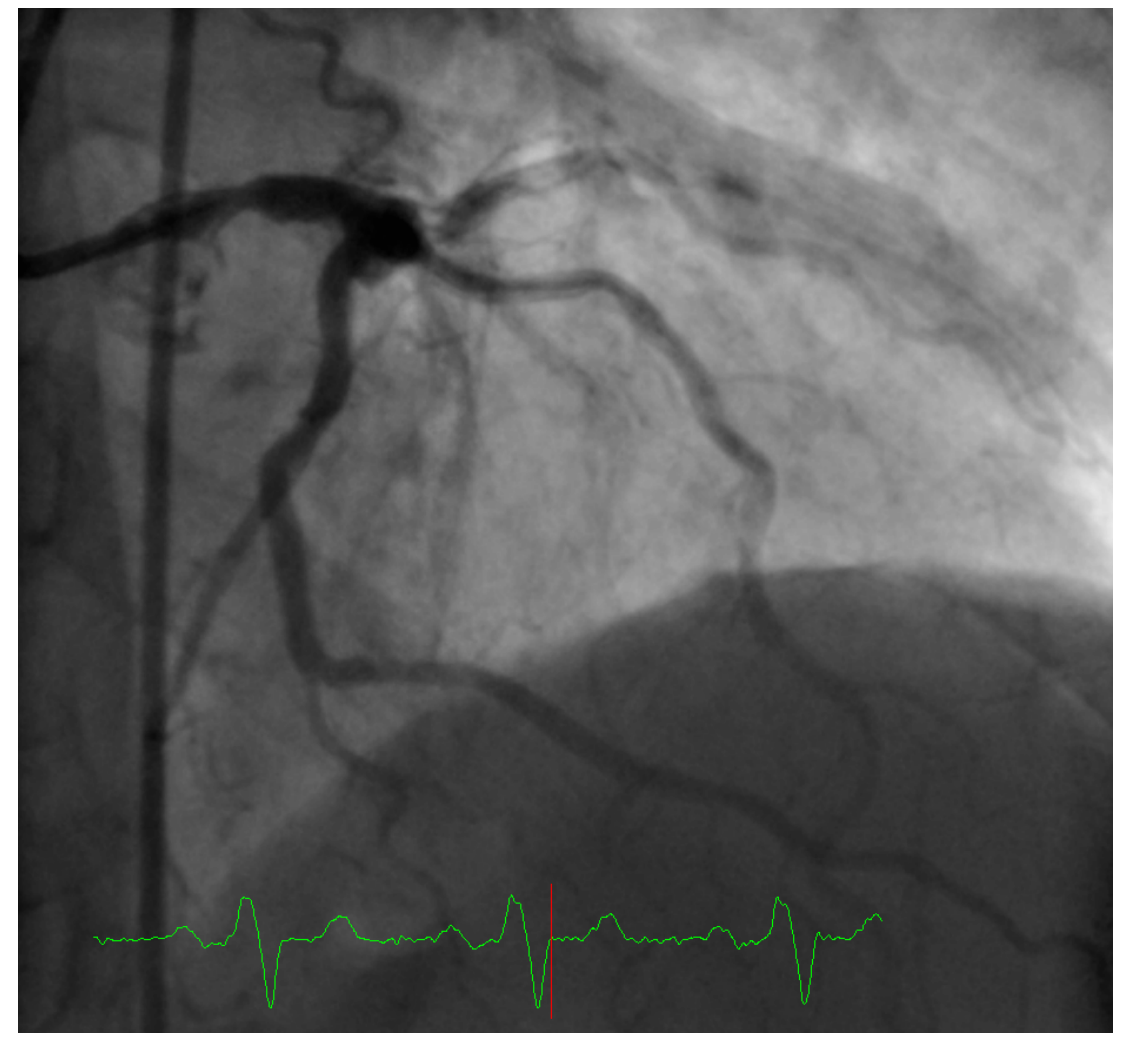

Fig. 3b. Mid shaft left main stenosis 


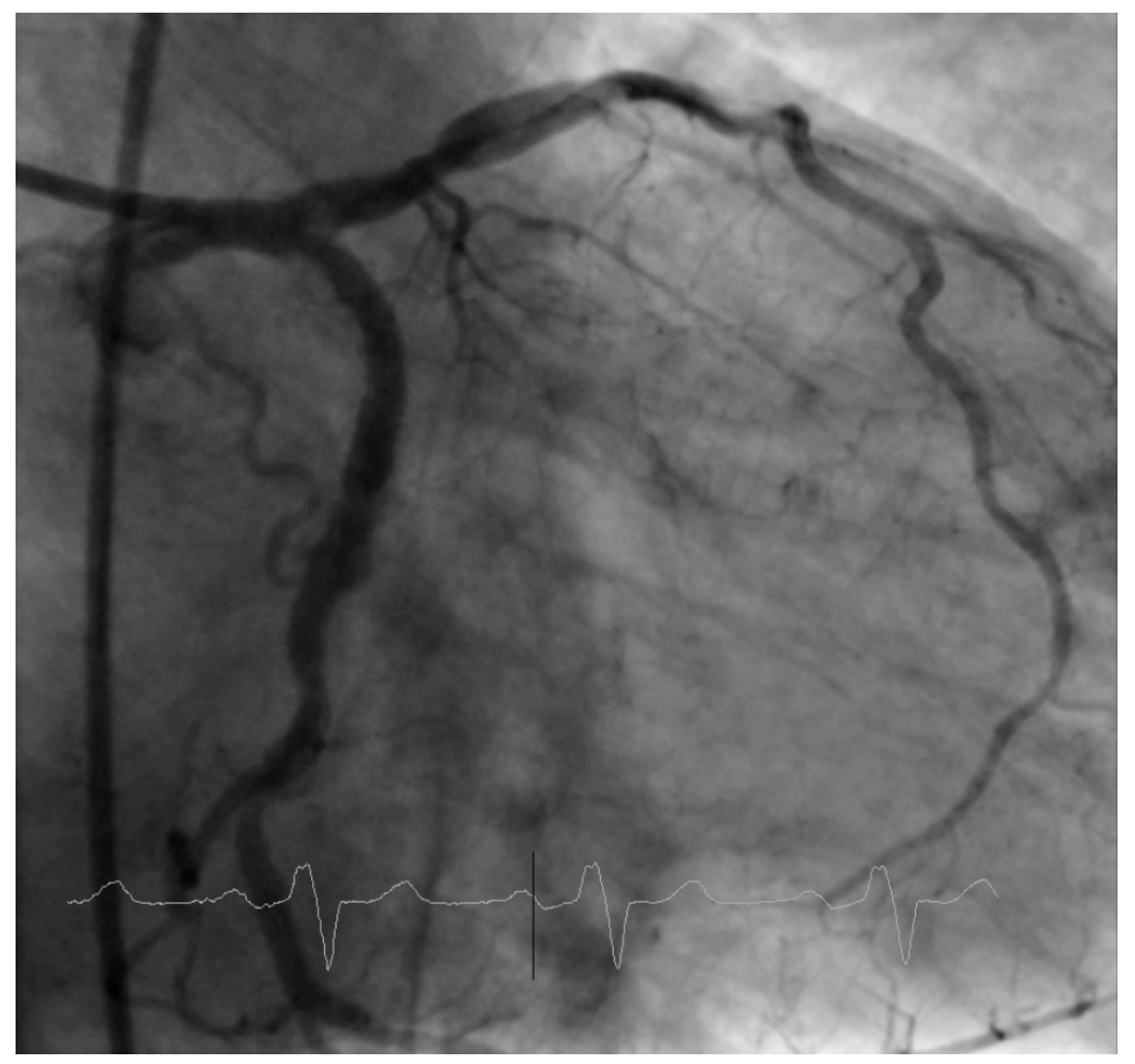

Fig. 3c. Drug eluting stent deployment in left main guided by IVUS

Case Four - anomalous coronary artery

A 63 year old male underwent coronary angiography after being successfully thrombolyzed for an inferior STEACS, 24 hours after his original pain onset. Coronary angiography via his right femoral artery showed a normal left coronary system but the origin of the right coronary artery (RCA) was not in the usual sinus. An Amplatz left catheter 2 (AL2) eventually revealed (Figure 4a) an anomalous RCA from the opposite sinus (ACAOS). A 95\% stenosis in the mid RCA was found and after trying various catheters, an EBU (extra back up) 3.5 guiding catheter (Medtronic ${ }^{\circledR}$ ), traditionally a left coronary catheter, made it possible for a successful intervention and the placement of a coronary stent (Figure $4 \mathrm{~b}$ and 4c). A CTCA (Figure 4d) was performed to ascertain the course of the RCA and confirmed ACAOS. Percutaneous coronary intervention in anomalous coronary arteries required innovative use of guiding catheters. 


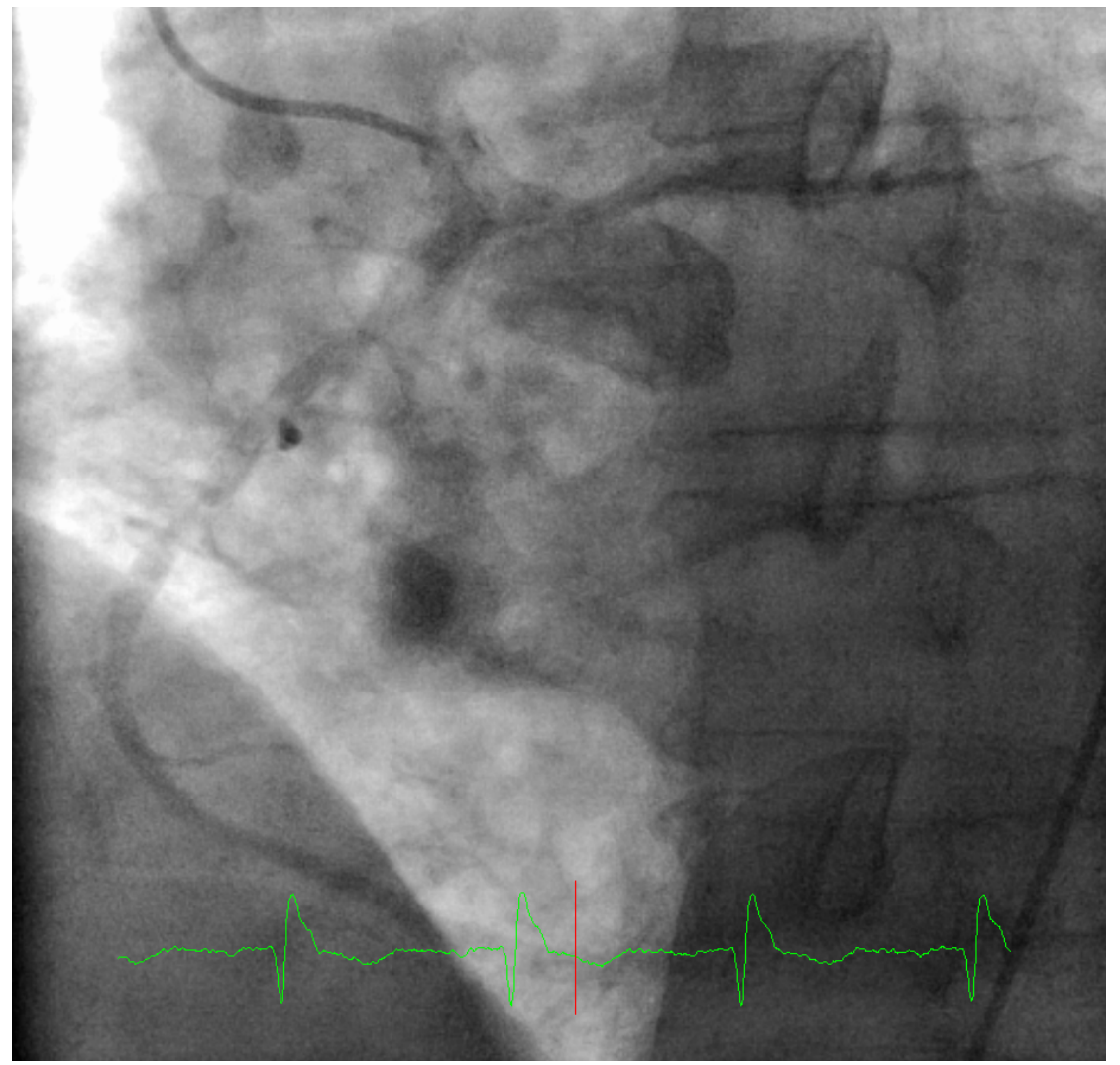

Fig. 4a. Right coronary artery injection with a 5Fr AL2 catheter showing an anomalous right coronary origin with impossible selective engagement 


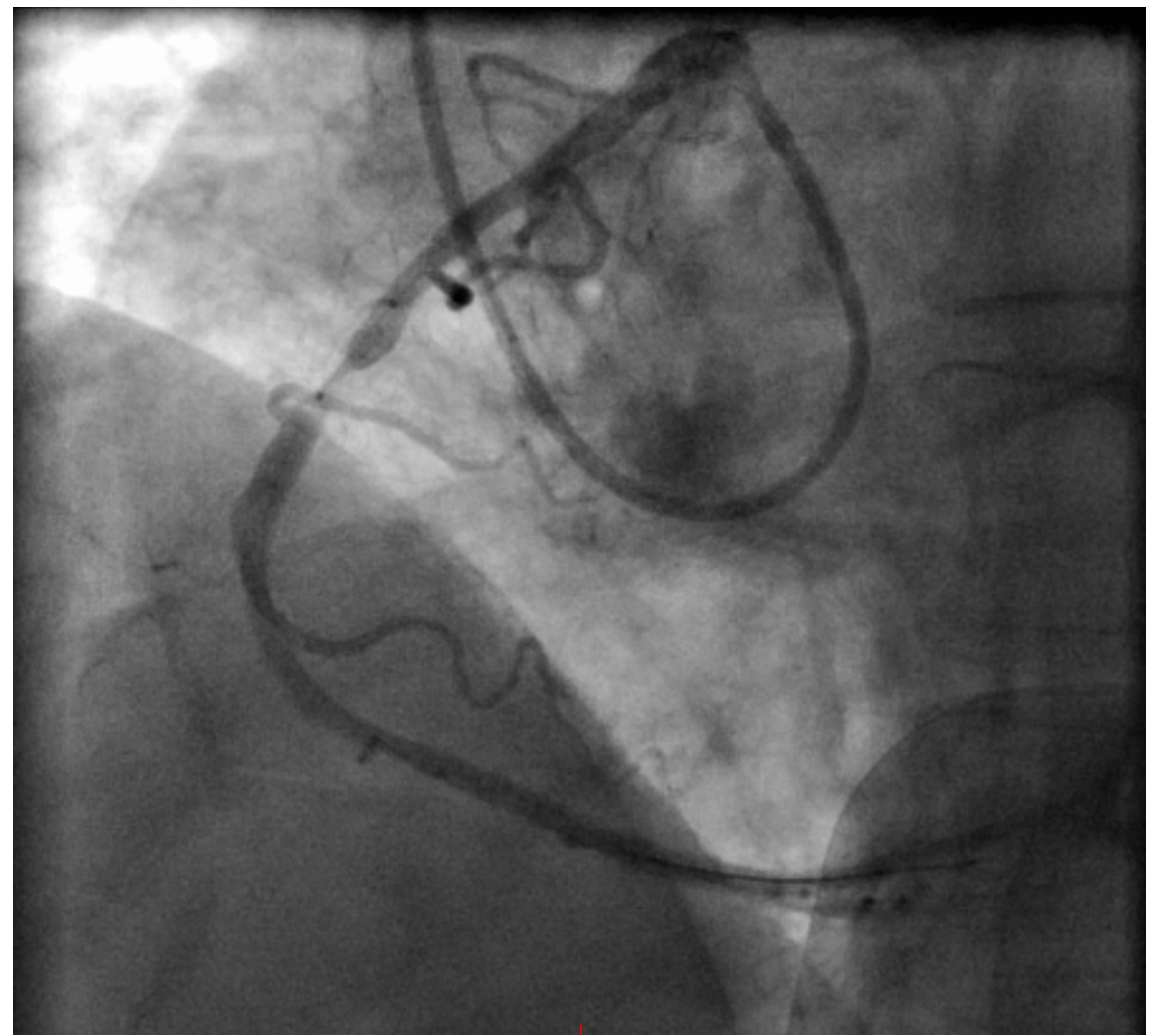

Fig. 4b. A 6Fr EBU catheter used to engage the anomalous origin. Traditional right coronary catheters would not have been useful. 


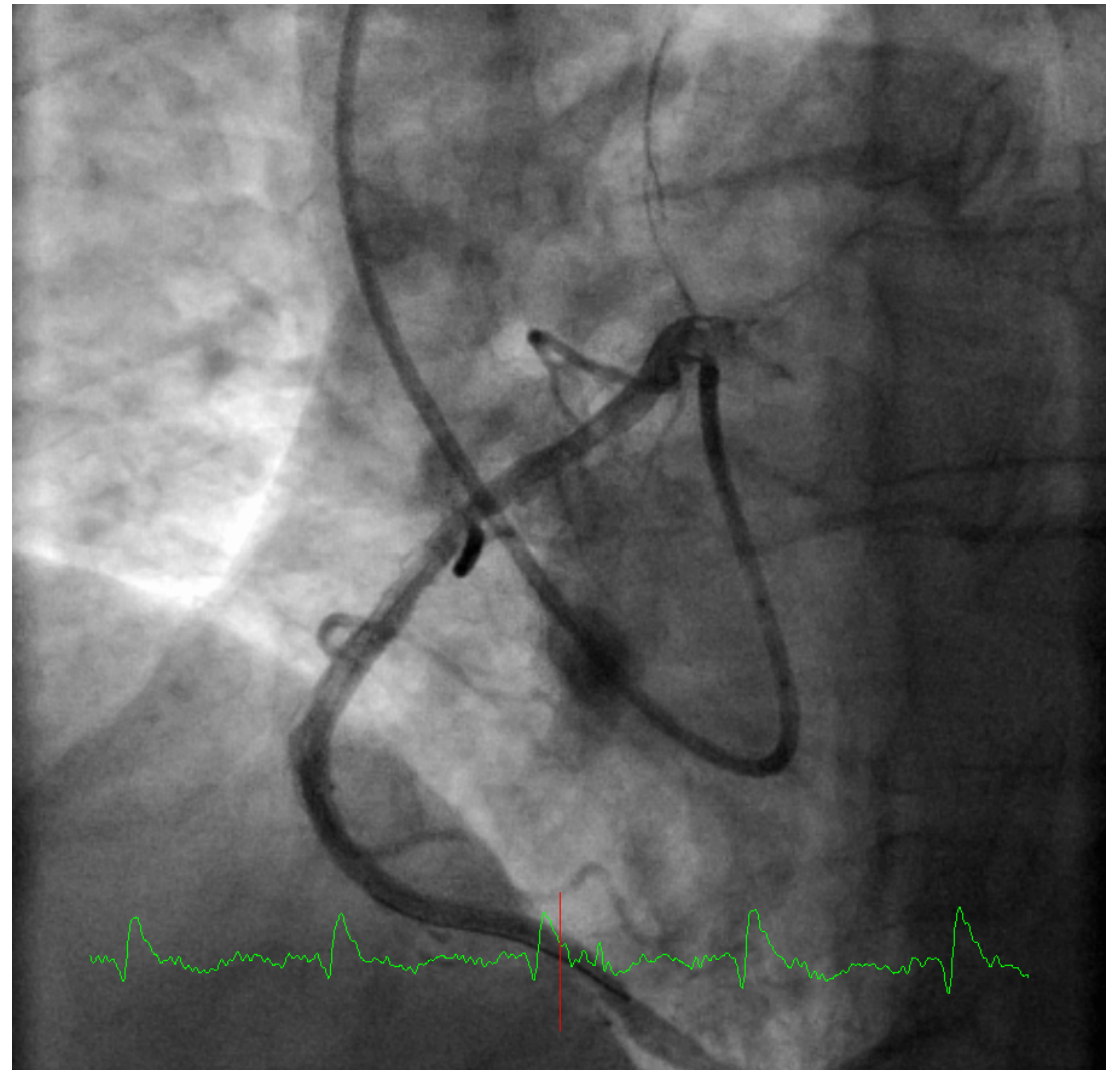

Fig. 4c. Successful placement of a drug eluting stent in the mid RCA with no residual stenosis. 


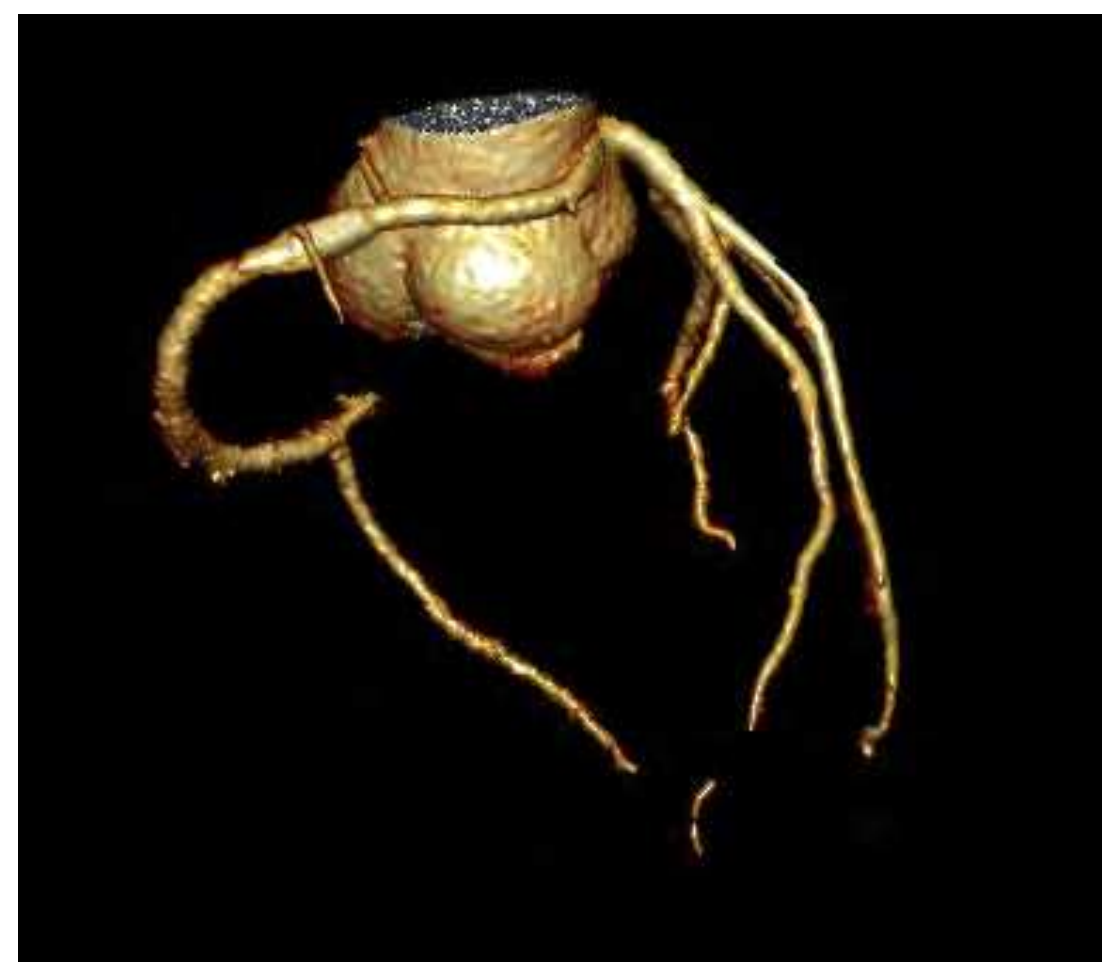

Fig. 4d. CTCA 3D reconstruction shows the origin and course of the anomalous right coronary artery clearly and defines its ante-aortic course.

Case Five - CTCA in graft assessment

A 69 year old male developed atypical chest pain 12 months after his coronary bypass graft (LIMA-LAD; RA-ramus; SVG-OM1). During the initial angiographic assessment he underwent IVUS of his left main and left anterior descending artery indeterminate lesions. IVUS showed his LM to be $5.44 \mathrm{~mm} 2$ and LAD $3.96 \mathrm{~mm} 2$. These were thought be suggest significant stenoses. To investigate his current atypical chest pain an MPS (Figure 5a) was performed which showed no inducible ischaemia or symptoms. A CTCA (Figure 5b) was performed which however suggested possible occluded LIMA graft. A coronary angiogram and graft study (Figure $5 \mathrm{c}$ and $5 \mathrm{~d}$ ) confirmed this finding that the LIMA graft had become atretic and normal coronary flow seen in the LAD. His other grafts were patent as was shown on the CTCA. This case demonstrated the value of CTCA in identifying graft patency and position, often facilitating the location of the graft anastomosis at the aorta. The atypical symptoms, patent coronary arteries and grafts, correlated well with his negative functional study. The LIMA-LAD graft probably underwent atresia as a result of no physiological implication to his intermediate LM and LAD lesions even though the diameters measured fulfilled conventional criteria for significant lesions. 


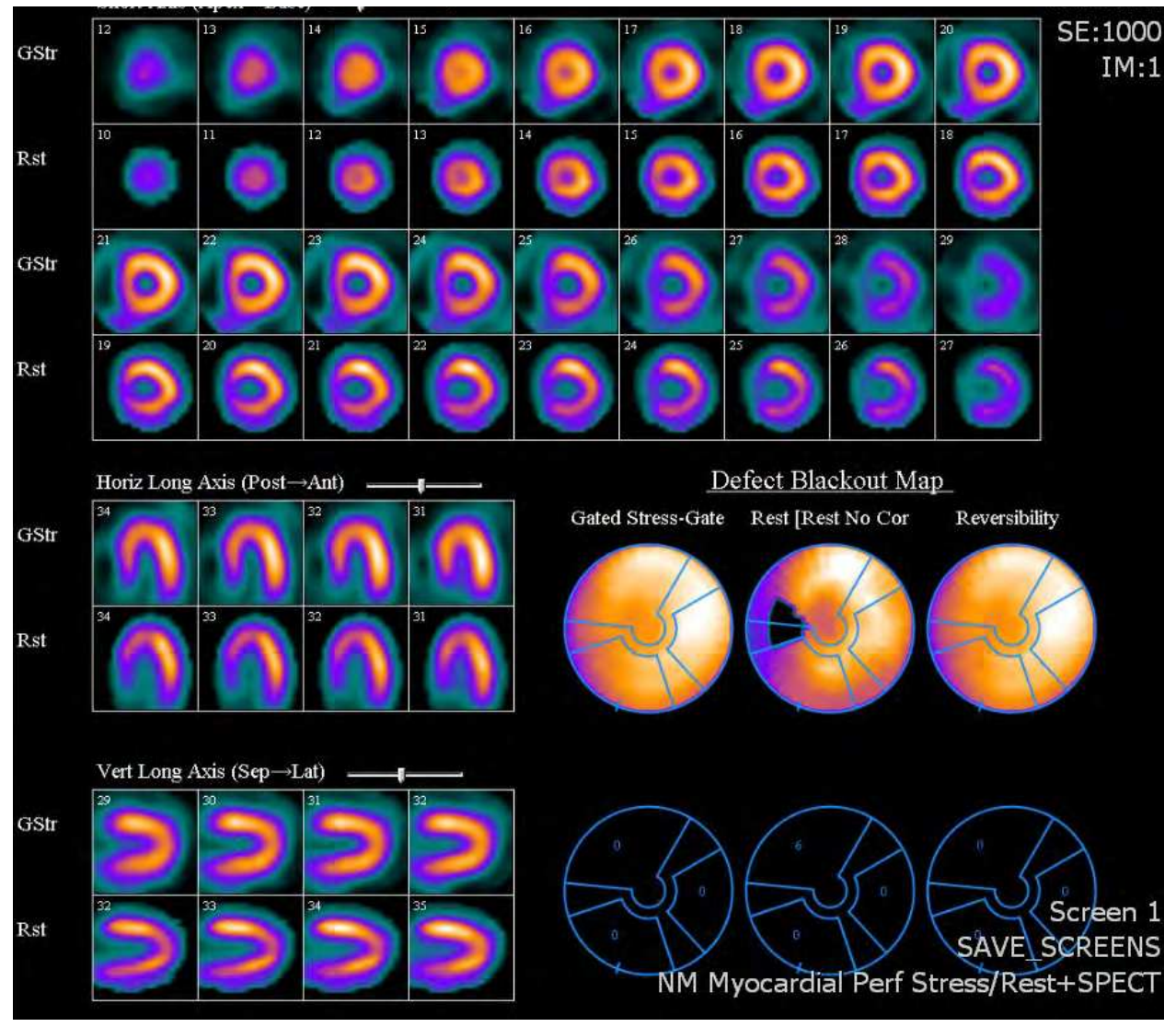

Fig. 5a. Myoperfusion study with no significant inducible ischaemia. 


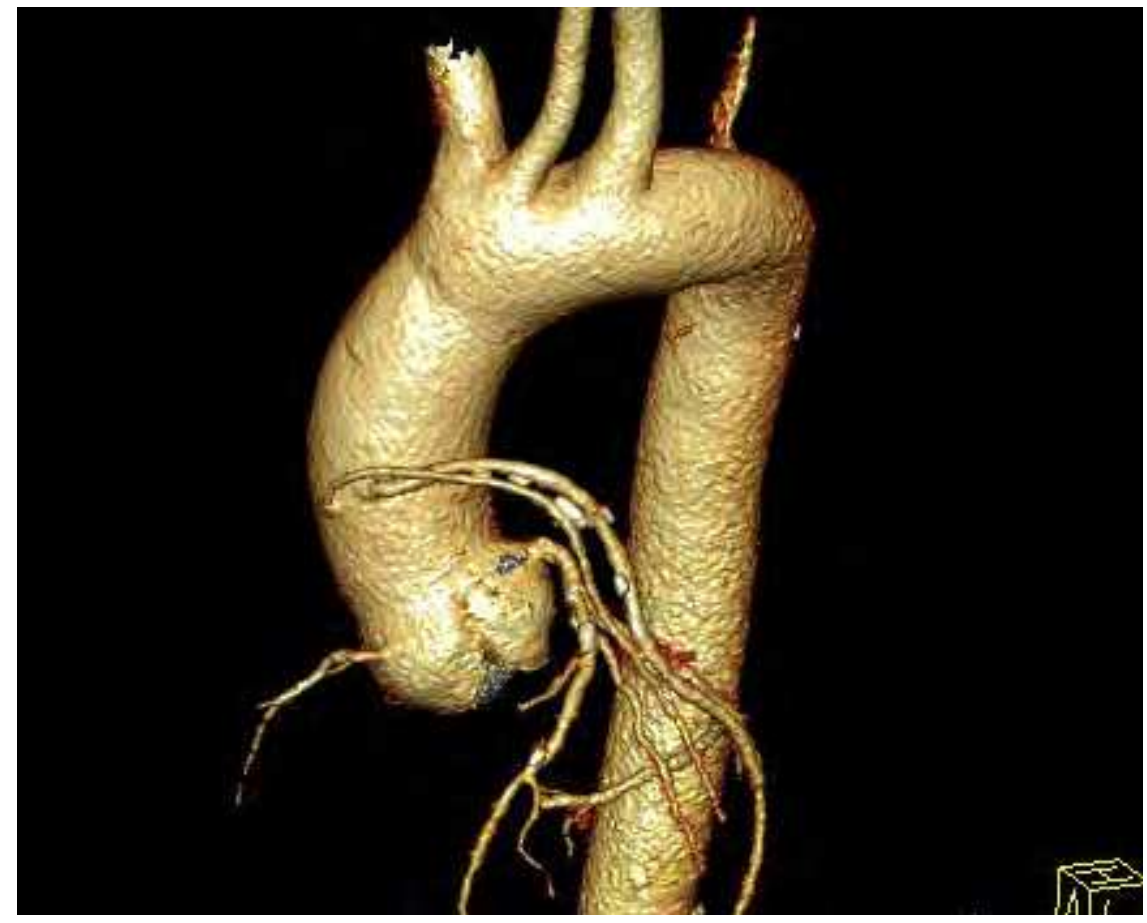

Fig. 5b. Position of two aortic grafts demonstrated clearly on CTCA. No LIMA flow demonstrated. 


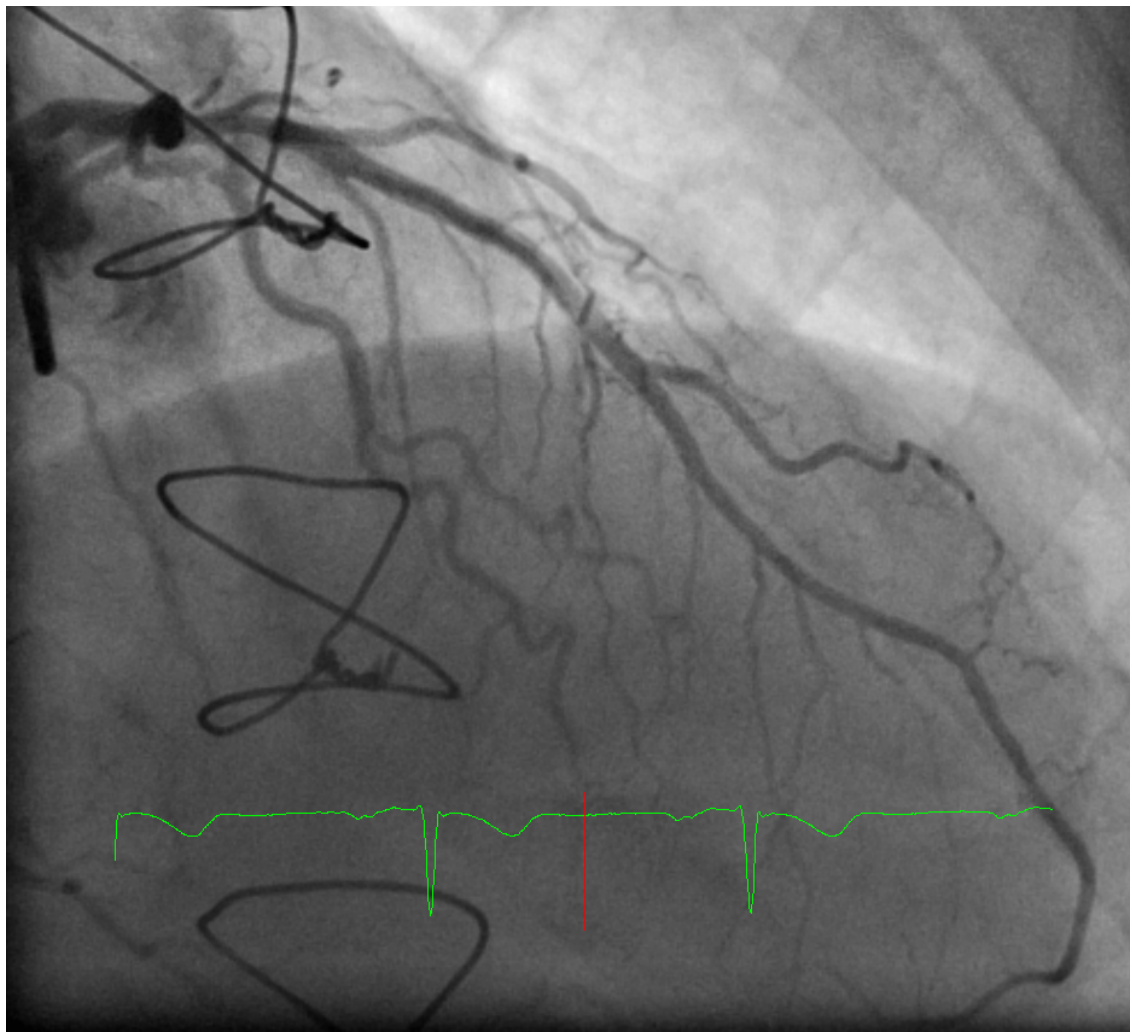

Fig. 5c. LAD artery with no obvious proximal stenosis and normal coronary flow. 


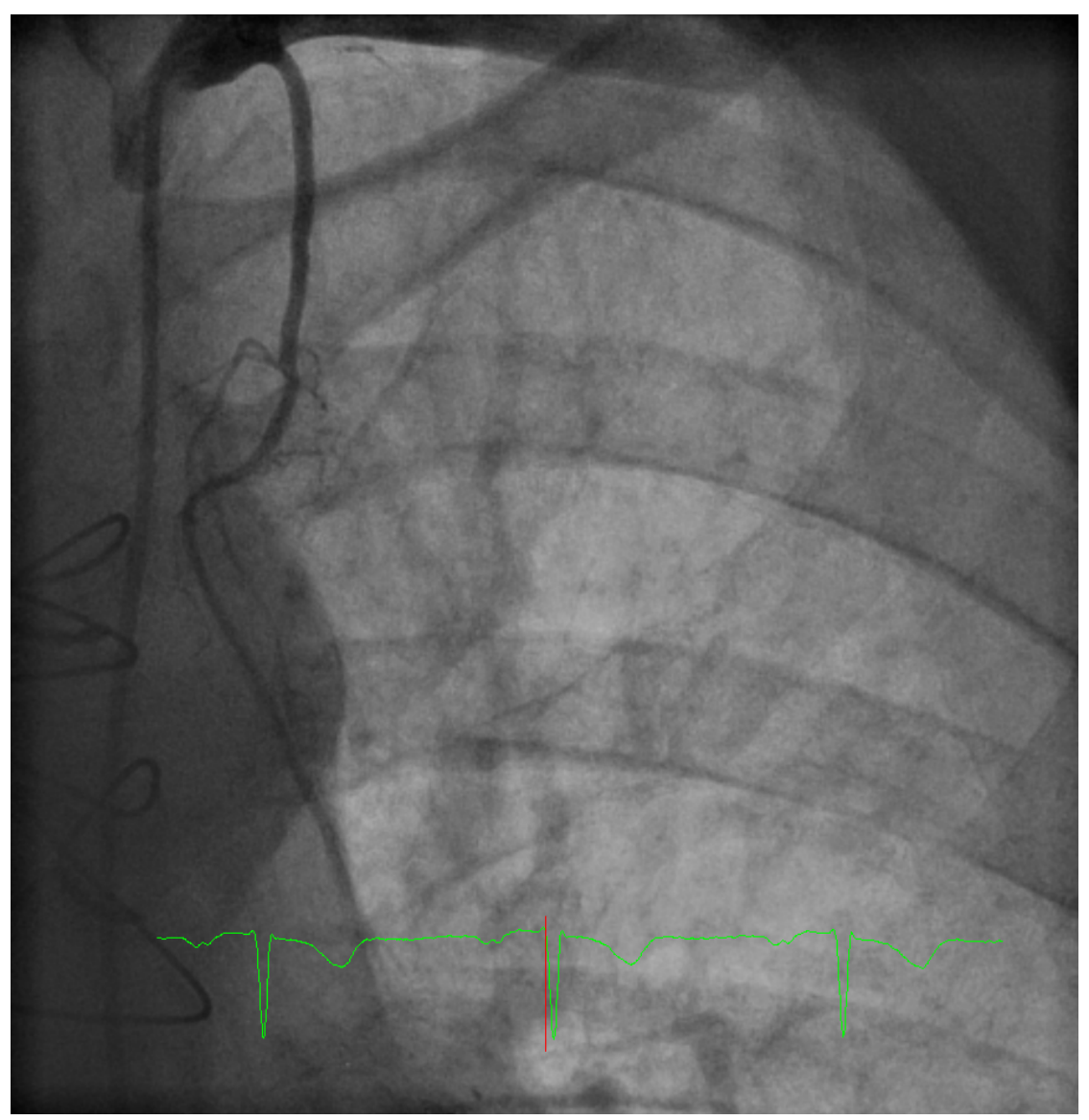

Fig. 5d. Small atretic LIMA.

Case Six - balanced ischaemia on MPS in a high risk patient

A 67 year old male with 20 years of diabetes mellitus II and 40 pack year history of smoking presented with six months of worsening exertional dyspnoea and chest pain. A myoperfusion study performed at a satisfactory level of workload demonstrated a small area of mildly reversible ischaemia in the inferolateral area. Given the abnormal findings, the patient proceeded to coronary angiography. This revealed severe distal left main artery stenosis, with a subtotally occluded left circumflex and a proximal severe RCA stenosis. Left ventricular function was normal. The extent and severity of disease was of prognostic significance. The patient underwent uneventful coronary bypass grafting and was discharged from the hospital one week after. This patient exhibited a high pretest probability based on the clinical profile. Whilst the myoperfusion study was suggestive, it underestimated the extent of disease likely due to the balanced ischaemia from the RCA and LM stenoses. Complex distal left main stenosis, especially bifurcation stenosis, is best treated with surgical revascularization. 


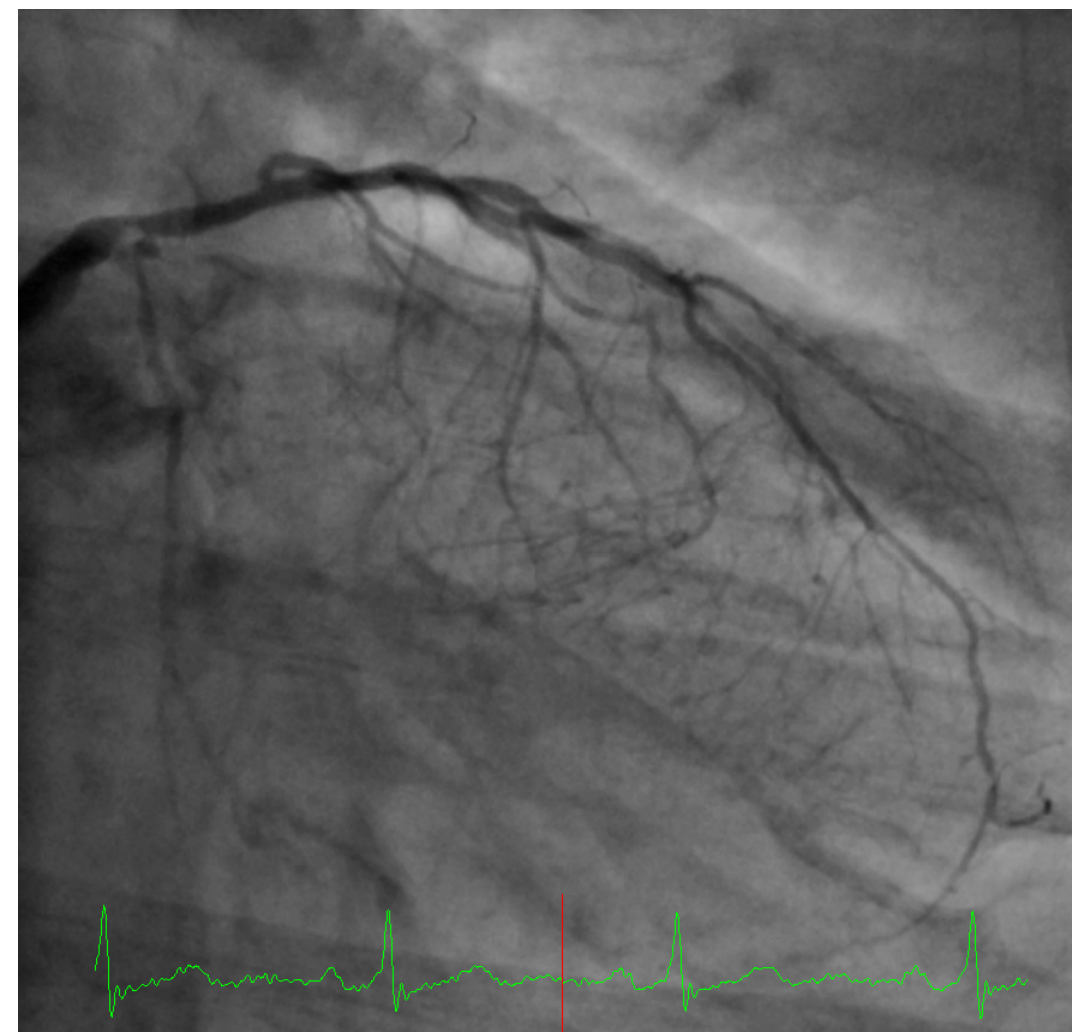

Fig. 6a. Distal left main eccentric stenosis and ostial circumflex stenosis. 


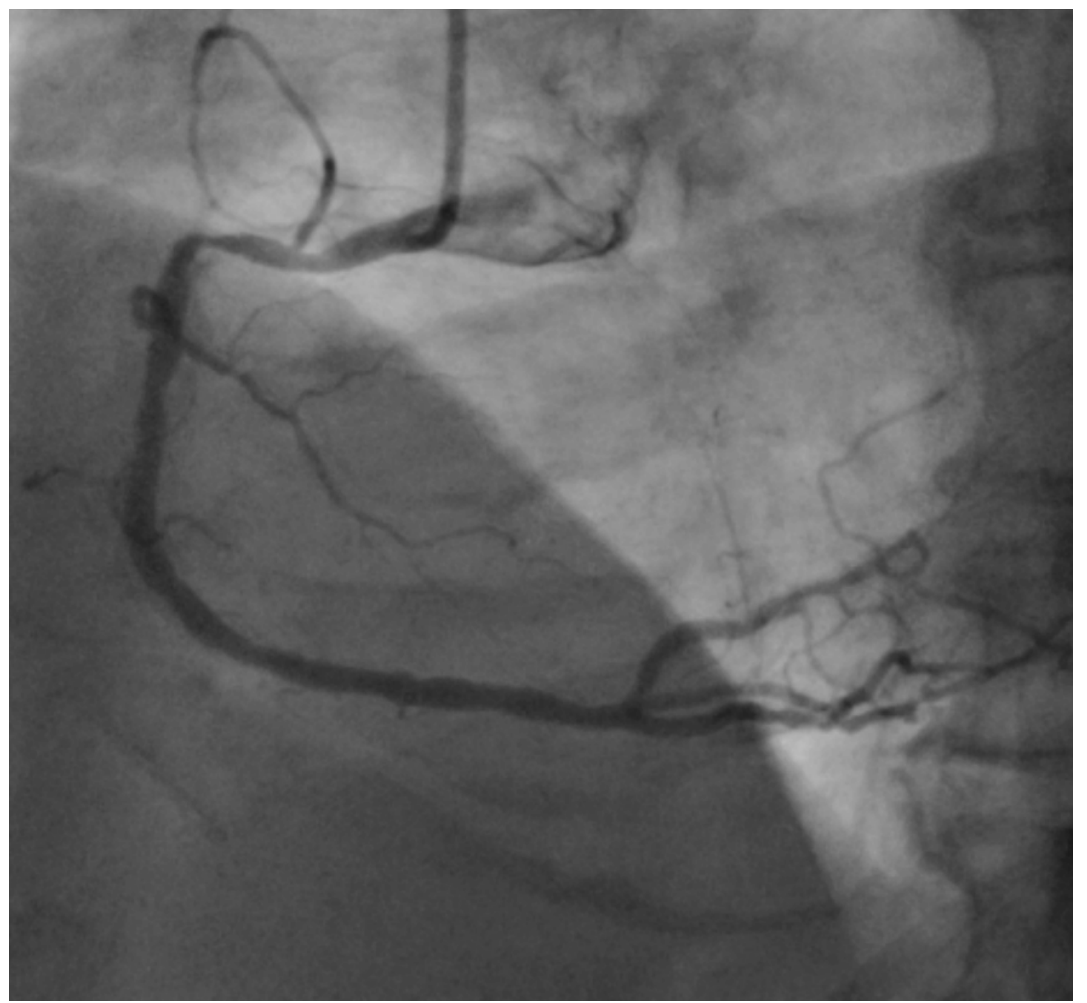

Fig. 6b. Proximal right coronary artery stenosis 


\section{Conclusion}

Coronary angiography remains the most accurate diagnostic modality for coronary artery disease. It provides a definitive assessment of coronary artery lumen and provides an avenue to percutaneous intervention. It is pivotal in the treatment on unstable or acute coronary syndromes and life saving in cardiogenic shock and STEACSs. Indications for invasive coronary angiography have changed incrementally over the decade since ACC/AHA guidelines on the topic were published. The advent of noninvasive CTCA has changed the landscape for the diagnosis of CAD but CTCAs seem destined only for the low to intermediate risk patients. Coronary angiography also serves a pivotal role in the burgeoning field of percutaneous structural cardiac interventions, especially percutaneous valve implants.

\section{References}

Andreini D, Pontone G, Bartorelli AL, Agostoni P, Mushtaq S, Bertella E, Trabattoni D, Cattadori G, Cortinovis S, Annoni A, et al. (2009). Sixty-Four-Slice Multidetector Computed Tomography: An Accurate Imaging Modality for the Evaluation of Coronary Arteries in Dilated Cardiomyopathy of Unknown Etiology Circ Cardiovasc Imaging 2(3): 199 - 205.

Anderson JL, Adams CD, et al. (2011). 2011 ACCF/AHA Focused Update Incorporated into the ACC/AHA 2077 Guidelines for the management of patients with unstable angina/Non-ST Elevation myocardial infarction, A report of the American College of Cardiology Foundation/American Heart Association Task Force on Practice Guidelines, Circulation. 2011; 123 [Epub ahead of print]

ASSENT-4 investigators, (2006). Primary versus tenecteplase-facilitated percutaneous coronary intervention in patients with ST-segment elevation acute myocardial infarction (ASSENT-4 PCI): randomised trial. Lancet 367:569-578.

Aurore A, Jabre P, Liot P, Margenet A, Lecarpentier E, Combes X. (2011). Predictive factors for positive coronary angiography in out-of-hospital cardiac arrest patients. Eur J Emerg Med. 18(2):73-6.

Bernard SA, Gray TW, Buist MD, Jones BM, Silvester W, Gutteridge G, et al. (2002). Treatment of comatose survivors of out-of-hospital cardiac arrest with induced hypothermia. N Engl J Med 346: 557 - 563

Bittl JA, Maron DJ. (2010). Having It Both Ways J. Am. Coll. Cardiol., 55(9): 865 - 866.

Boden WE, O'Rourke RA, Teo KK, et al. (2007). Optimal medical therapy with or without PCI for stable coronary disease. N Engl J Med 356:1503-1516

Boersma E, Kertai MD, Schouten O, Bax JJ, Noordzij P, Steyerberg EW, Schinkel AF, van Santen M, Simoons ML, Thomson IR, Klein J, van Urk H, Poldermans D. (2005). Perioperative cardiovascular mortality in noncardiac surgery: validation of the Lee cardiac risk index. Am J Med 118:1134-1141.

Bøhmer E, Hoffmann P, Abdelnoor M, Arnesen H, Halvorsen S. (2010). Efficacy and safety of immediate angioplasty versus ischemia-guided management after thrombolysis in acute myocardial infarction in areas with very long transfer distances: results of 
the NORDISTEMI (NORwegian study on DIstrict treatment of ST-Elevation Myocardial Infarction) J Am Coll Cardiol 55:102-110.

Bonow RO, Carabello BA, Kanu C, de Leon AC Jr, Faxon DP, Freed MD, Gaasch WH, Lytle BW, Nishimura RA, O'Gara PT, O'Rourke RA, Otto CM, Shah PM, Shanewise JS, Smith SC Jr, Jacobs AK, Adams CD, Anderson JL, Antman EM, Faxon DP, Fuster V, Halperin JL, Hiratzka LF, Hunt SA, Lytle BW, Nishimura R, Page RL, Riegel B. (2006). ACC/AHA 2006 guidelines for the management of patients with valvular heart disease: a report of the American College of Cardiology/American Heart Association Task Force on Practice Guidelines (writing Committee to Revise the 1998 guidelines for the management of patients with valvular heart disease) developed in collaboration with the Society of Cardiovascular Anesthesiologists endorsed by the Society for Cardiovascular Angiography and Interventions and the Society of Thoracic Surgeons. J Am Coll Cardiol. 48: e1-e148.

Borgia, F, Goodman SC, Halvorsen S, Cantor WJ, Piscione F, Le May MR, Fernandez-Aviles F, Sanchez PL, Dimopoulos K, Scheller B, Armstrong PW and Di Mario C. (2010). Early routine Percutaneous coronary intervention after fibrinolysis vs. standard therapy in ST-segment elevation myocardial infarction: a meta-analysis, Eur Heart J 31 (17):2156-2169

Budoff MJ, Dowe D, Jollis JG, et al. (2008). Diagnostic performance of 64-multidetector-row coronary computed tomographic angiography for evaluation of coronary artery stenosis in individuals without known coronary artery disease. J Am Coll Cardiol 52:1724-32.

Cannon CP. (2004). Revascularisation for everyone? Eur Heart J 25:1471-1472

Cantor WJ, Fitchett D, Borgundvaag B, Ducas J, Heffernan M, Cohen EA, Morrison LJ, Langer A, Dzavik V, Mehta SR, Lazzam C, Schwartz B, Casanova A, Goodman SG. (2009). Routine early angioplasty after fibrinolysis for acute myocardial infarction. N Engl J Med 360:2705-2718.

Carver A, Rafelt S, Gershlick AH, et al. REACT Investigators. (2009). Longer-term follow-up of patients recruited to the REACT (Rescue Angioplasty Versus Conservative Treatment or Repeat Thrombolysis) trial J Am Coll Cardiol 54:118-126.

Chan MY, Sun JL, Newby LK, Shaw LK, Lin M, Peterson ED, Califf RM, Kong DF, Roe MT. (2009). Long-term mortality of patients undergoing cardiac catheterization for STelevation and non-ST elevation myocardial infarction, Circulation. 19(24):3110-7

Damman P, Hirsch A, Windhausen F, Tijssen JGP, de Winter RJ, ICTUS Investigators. (2010). 5-year clinical outcomes in the ICTUS (Invasive versus Conservative Treatment in Unstable coronary Syndromes) trial: a randomized comparison of an early invasive versus selective invasive management in patients with non-STsegment elevation acute coronary syndrome J Am Coll Cardiol 55:858-864.

de Winter RJ, Windhausen F, Cornel JH, et al (2005). Invasive versus Conservative Treatment in Unstable Coronary Syndromes (ICTUS) Investigators. Early invasive versus selectively invasive management for acute coronary syndromes. $\mathrm{N} \mathrm{Engl} \mathrm{J}$ Med 353: 1095-1104.

Desch S, Eitel I, Rahimi K, de Waha S, Schuler G, Thiele H, (2010). Timing of invasive treatment after fibrinolysis in ST elevation myocardial infarction - a meta-analysis 
of immediate or early routine versus deferred or ischaemia-guided randomized controlled trials, Heart, 96(21):1695-1702

Di Mario C, Dudek D, Piscione F, Mielecki W, Savonitto S, Murena E, Dimopoulos K, Manari A, Gaspardone A, Ochala A, Zmudka K, Bolognese L, Steg PG, Flather M. (2008). Immediate angioplasty versus standard therapy with rescue angioplasty after thrombolysis in the Combined Abciximab Reteplase Stent Study in Acute Myocardial Infarction (CARESS-in-AMI): an open, prospective, randomised, multicentre trial. Lancet 371:559-568

D'Souza SP, Mamas MA, Fraser DG, Fath-Ordoubadi F. (2010). Routine early coronary angioplasty versus ischaemia-guided angioplasty after thrombolysis in acute STelevation myocardial infarction: a meta-analysis Eur Heart J first published online October 28, 2010

Dumas F, Cariou A, Manzo-Silberman S, et al. (2010) Immediate percutaneous coronary intervention is associated with better survival after out-of-hospital cardiac arrest: insights from the PROCAT (Parisian Region Out of hospital Cardiac ArresT) registry. Circ Cardiovasc Interv 3:200-7

Ellis SG, Tendera M, de Belder MA, van Boven AJ, Widimsky P, Janssens L, Andersen HR, Betriu A, Savonitto S, Adamus J, Peruga JZ, Kosmider M, Katz O, Neunteufl T, Jorgova J, Dorobantu M, Grinfeld L, Armstrong P, Brodie BR, Herrmann HC, Montalescot G, Neumann FJ, Effron MB, Barnathan ES, Topol EJ. (2008). Facilitated PCI in patients with ST-elevation myocardial infarction. N Engl J Med 358:22052217.

Fernandez-Aviles F, Alonso JJ, Castro-Beiras A, Vazquez N, Blanco J, Alonso-Briales J, Lopez-Mesa J, Fernandez-Vazquez F, Calvo I, Martinez-Elbal L, San Roman JA, Ramos B. (2004). Routine invasive strategy within 24 hours of thrombolysis versus ischaemia-guided conservative approach for acute myocardial infarction with ST-segment elevation (GRACIA-1): a randomised controlled trial. Lancet 364:1045-1053

Fox KA, Clayton TC, Damman P, Pocock SJ, de Winter RJ, Tijssen JG, Lagerqvist B,Wallentin L. (2010). Long-term outcome of a routine versus selective invasive strategy in patients with non-ST-segment elevation acute coronary syndrome a meta-analysis of individual patient data. J Am Coll Cardiol 55:2435-2445.

Garot P, Lefevre T, Eltchaninoff H, Morice MC, Tamion F, Abry B, Lesault PF, Le Tarnec JY, Pouges C, Margenet A, Monchi M, Laurent I, Dumas P, Garot J, Louvard Y. (2007). Six-month outcome of emergency percutaneous coronary intervention in resuscitated patients after cardiac arrest complicating ST-elevation myocardial infarction. Circulation. 115: 1354-1362.

Gershlick AH, Stephens-Lloyd A, Hughes S, et al. (2005). Rescue angioplasty after failed thrombolytic therapy for acute myocardial infarction. N Engl J Med. 353:275868

Hoenig MR, Doust JA, Aroney CN, Scott IA. (2006). Early invasive versus conservative strategies for unstable angina \& non-ST-elevation myocardial infarction in the stent era. Cochrane Database Syst Rev 3: CD004815. 
Hosmane VR, Mustafa NG, Reddy VK, et al. (2009). Survival and neurologic recovery in patients with ST-segment elevation myocardial infarction resuscitated from cardiac arrest. J Am Coll Cardiol 53:409-15.

Hulten EA, Carbonaro S, Petrillo SP, Mitchell JD, Villines TC. (2011). Prognostic value of cardiac computed tomography, A systematic review and meta-analysis, J. Am. Coll. Cardiol 57:1237-1247.

ILCOR, Part 9: Acute coronary syndromes 2010 International Consensus on Cardiopulmonary Resuscitation and Emergency Cardiovascular Care Science with Treatment Recommendations_Nolan, JP, Hazinski MF, et al, Part 1: Executive summary 2010 International Consensus on Cardiopulmonary Resuscitation and Emergency Cardiovascular Care Science With Treatment Recommendations Resuscitation 81S (2010) e175-e212Resuscitation 81S (2010) e1-e25

Keeley EC, Boura JA, Grines CL. (2006). Comparison of primary and facilitated percutaneous coronary interventions for ST-elevation myocardial infarction: quantitative review of randomised trials Lancet 367:579-588

Leon MB, Smith CR, Mack M, et al. (2010). Transcatheter aortic-valve implantation for aortic stenosis in patients who cannot undergo surgery. $N$ Engl J Med 2010; DOI:10.1056/NEJMoa1008232

McFalls EO, Ward HB, Moritz TE, Goldman S, Krupski WC, Littooy F, Pierpont G, Santilli S, Rapp J, Hattler B, Shunk K, Jaenicke C, Thottapurathu L, Ellis N, Reda DJ, Henderson WG. (2004). Coronary-artery revascularization before elective major vascular surgery. N Engl J Med 351:2795 - 2804.

Mehta SR, Cannon CP, Fox KA, Wallentin L, Boden WE, Spacek R, Widimsky P, McCullough PA, Hunt D, Braunwald E, Yusuf S. (2005). Routine vs selective invasive strategies in patients with acute coronary syndromes: a collaborative meta-analysis of randomized trials. JAMA 293:2908-2917.

Mehta SR, Granger CB, Boden WE, et al. (2009). Early versus delayed invasive intervention in acute coronary syndromes. N Engl J Med. 360: 2165-75.

Meijboom WB, Meijs MF, Schuijf JD, et al. (2008) Diagnostic accuracy of 64-slice computed tomography coronary angiography: a prospective, multicenter, multivendor study. J Am Coll Cardiol 52:2135-44

Meijboom WB, Mollet NR, Van Mieghem CAG, Kluin J, Weustink AC, Pugliese F, Vourvouri E, Cademartiri F, Bogers AJJC, Krestin GP, et al. (2006). Pre-Operative Computed Tomography Coronary Angiography to Detect Significant Coronary Artery Disease in Patients Referred for Cardiac Valve Surgery J. Am. Coll. Cardiol., 48(8): 1658 - 1665.

Miller JM, Rochitte CE, Dewey M, et al. (2008). Diagnostic performance of coronary angiography by 64-row CT. N Engl J Med 359:2324-36.

Montalescot G, Cayla G, Collet JP, et al. (2009). Immediate vs delayed intervention for acute coronary syndromes: a randomized clinical trial. JAMA. 302:947-54.

Mowatt G, Cook JA, Hillis GS, et al. (2008). 64-Slice computed tomography angiography in the diagnosis and assessment of coronary artery disease: systematic review and meta-analysis. Heart 94:1386-93. 
Neumann FJ, Kastrati A, Pogatsa-Murray G, et al. (2003). Evaluation of prolonged antithrombotic pretreatment ("cooling-off" strategy) before intervention in patients with unstable coronary syndromes: a randomized controlled trial. JAMA. 290:15939.

Pell JP, Sirel JM, Marsden AK, Ford I, Walker NL, Cobbe SM. (2003). Presentation, management, and outcome of out of hospital cardiopulmonary arrest: comparison by underlying aetiology. Heart 89:839-42

Poldermans D, Bax JJ, Boersma E, De Hert S, Eeckhout E, Fowkes G, Gorenek B, Hennerici MG, Iung B, Kelm M, Kjeldsen KP, Kristensen SD, Lopez-Sendon J, Pelosi P, Philippe F, Pierard L, Ponikowski P, Schmid JP, Sellevold OF, Sicari R, Van den Berghe G, Vermassen F, Hoeks SE, Vanhorebeek I. (2009). Guidelines for preoperative cardiac risk assessment and perioperative cardiac management in noncardiac surgery: the Task Force for Preoperative Cardiac Risk Assessment and Perioperative Cardiac Management in Non-cardiac Surgery of the European Society of Cardiology (ESC) and endorsed by the European Society of Anaesthesiology (ESA). Eur Heart J 30:2769-2812.

Reynolds JC, Callaway CW, El Khoudary SR, Moore CG, Alvarez RJ, Rittenberger JC. (2009). Coronary angiography predicts improved outcome following cardiac arrest: propensity-adjusted analysis. J Intensive Care Med 24:179-86.

Spaulding CM, Joly LM, Rosenberg A, et al. (1997). Immediate coronary angiography in survivors of out-of-hospital cardiac arrest. N Engl J Med 336:1629-33.

Stub D, Hengel C, Chan W, Jackson D, Sanders K, Dart AM, Hilton A, Pellegrino V, Shaw JA, Duffy SJ, Bernard S, Kaye DM. (2011). Usefulness of cooling and coronary catheterization to improve survival in out-of-hospital cardiac arrest. Am J Cardiol. 107(4):522-7. Epub 2010 Dec 22.

Sunde K, Pytte M, Jacobsen D, et al. (2007) Implementation of a standardised treatment protocol for post resuscitation care after out-of-hospital cardiac arrest. Resuscitation 73:29- 39 .

Taylor AJ, Cerqueira M, Hodgson JM, et al. (2010).

ACCF/SCCT/ACR/AHA/ASE/ASNC/NASCI/SCAI/SCMR 2010 appropriate use criteria for cardiac computed tomography: a report of the American College of Cardiology Foundation Appropriate Use Criteria Task Force, the Society of Cardiovascular Computed Tomography, the American College of Radiology, the American Heart Association, the American Society of Echocardiography, the American Society of Nuclear Cardiology, the North American Society for Cardiovascular Imaging, the Society for Cardiovascular Angiography and Interventions, and the Society for Cardiovascular Magnetic Resonance J Am Coll Cardiol 56:1864-1894.

Thompson PL. (2010). The invasive approach to acute coronary syndrome: true promise or false premise? Med J Aust; 192 (12): 694-695.

Vahanian A, Baumgartner H, Bax J, Butchart E, Dion R, Filippatos G, Flachskampf F, Hall R, Iung B, Kasprzak J, Nataf P, Tornos P, Torracca L, Wenink A. (2007). Grupo de Trabajo sobre el Tratamiento de las Valvulopatías de la Sociedad Europea de 
Cardiología: guidelines on the management of valvular heart disease. Eur Heart J. 28: $230-268$.

Wijeysundera HC, Vijayaraghavan R, Nallamothu BK, et al. (2007). Rescue angioplasty or repeat fibrinolysis after failed fibrinolytic therapy for ST-segment myocardial infarction: a meta-analysis of randomized trials. J Am Coll Cardiol. 49:422-30

Wolfrum S, Pierau C, Radke PW, Schunkert H, Kurowski V. (2008). Mild therapeutic hypothermia in patients after out-of-hospital cardiac arrest due to acute STsegment elevation myocardial infarction undergoing immediate percutaneous coronary intervention. Crit Care Med 36:1780-6 


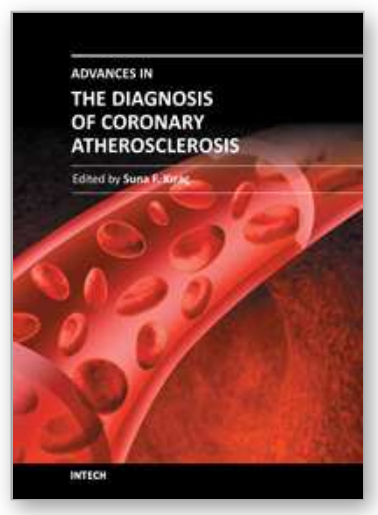

\author{
Advances in the Diagnosis of Coronary Atherosclerosis \\ Edited by Prof. Suna Kirac
}

ISBN 978-953-307-286-9

Hard cover, 378 pages

Publisher InTech

Published online 09, November, 2011

Published in print edition November, 2011

Coronary artery disease $(C A D)$ and its consequences are most important morbidity and mortality reasons in the developed and developing countries. To prevent hard end-points, early definitive diagnosis and optimum therapy play significant role. Novel advanced diagnostic tests which are biomarkers of inflammation, cell adhesion, cell activation and imaging techniques provide to get the best result in the detection and characterization of calcified or uncalcified atherosclerotic plaques. In spite of last developments in the imaging methods, coronary catheterization is still frequently performed. Following the first cardiac catheterization performed in 1844, date by date historical developments and the mechanics of cardiac catheterization techniques, risks associated with coronary angiography, and also, preventions and treatments of possible complications have been presented in this book. Other important issue is radiation exposure of patients and staff during coronary angiography and scintigraphy. Radiation dose reduction techniques, general radiation protection principles have been discussed in related chapters.

\title{
How to reference
}

In order to correctly reference this scholarly work, feel free to copy and paste the following:

Karl Poon and Darren Walters (2011). Indications for Coronary Angiography, Advances in the Diagnosis of Coronary Atherosclerosis, Prof. Suna Kirac (Ed.), ISBN: 978-953-307-286-9, InTech, Available from: http://www.intechopen.com/books/advances-in-the-diagnosis-of-coronary-atherosclerosis/indications-forcoronary-angiography

\section{INTECH}

open science | open minds

\section{InTech Europe}

University Campus STeP Ri

Slavka Krautzeka 83/A

51000 Rijeka, Croatia

Phone: +385 (51) 770447

Fax: +385 (51) 686166

www.intechopen.com

\section{InTech China}

Unit 405, Office Block, Hotel Equatorial Shanghai

No.65, Yan An Road (West), Shanghai, 200040, China

中国上海市延安西路65号上海国际贵都大饭店办公楼405单元

Phone: +86-21-62489820

Fax: $+86-21-62489821$ 
(C) 2011 The Author(s). Licensee IntechOpen. This is an open access article distributed under the terms of the Creative Commons Attribution 3.0 License, which permits unrestricted use, distribution, and reproduction in any medium, provided the original work is properly cited. 